\title{
Survival and recovery characteristics of Arcobacter butzleri in groundwater microcosms
}

\author{
Robert Darrell McElwain \\ West Virginia University
}

Follow this and additional works at: https://researchrepository.wvu.edu/etd

\section{Recommended Citation}

McElwain, Robert Darrell, "Survival and recovery characteristics of Arcobacter butzleri in groundwater microcosms" (2002). Graduate Theses, Dissertations, and Problem Reports. 1527.

https://researchrepository.wvu.edu/etd/1527

This Thesis is protected by copyright and/or related rights. It has been brought to you by the The Research Repository @ WVU with permission from the rights-holder(s). You are free to use this Thesis in any way that is permitted by the copyright and related rights legislation that applies to your use. For other uses you must obtain permission from the rights-holder(s) directly, unless additional rights are indicated by a Creative Commons license in the record and/ or on the work itself. This Thesis has been accepted for inclusion in WVU Graduate Theses, Dissertations, and Problem Reports collection by an authorized administrator of The Research Repository @ WVU. For more information, please contact researchrepository@mail.wvu.edu. 


\title{
SURVIVAL AND RECOVERY CHARACTERISTICS OF ARCOBACTER BUTZLERI IN GROUNDWATER MICROCOSMS
}

\author{
Robert Darrell McElwain \\ Thesis submitted to the Davis College of Agriculture, Forestry, and \\ Consumer Sciences at West Virginia University \\ in partial fulfillment of the requirements \\ for the degree of \\ Master of Science \\ In \\ Plant and Soil Sciences \\ with a concentration in Environmental Microbiology
}

Gary K. Bissonnette, Ph.D., Chair

Robert E. Anderson, Ph.D.

P. Brett Kenney, Ph.D.

Alan J. Sexstone, Ph.D.

Morgantown, West Virginia

2002

Keywords: Arcobacter, Groundwater, Survival, Selective media 


\section{ABSTRACT \\ SURVIVAL AND RECOVERY CHARACTERISTICS OF ARCOBACTER BUTZLERI IN GROUNDWATER MICROCOSMS}

\section{Robert Darrell McElwain}

The genus Arcobacter is considered by many public health officials as an etiological agent of gastroenteritis in individuals consuming contaminated food or water. However, relatively little is known about the persistence, detection, and ecology of this genus, particularly in groundwater. In laboratory microcosm studies it was determined that the survival of $A$. butzleri in nutrient-limited groundwater can exceed that of the traditional water quality indicator organism, Escherichia coli. An inverse relationship between survival and water temperature was observed for both organisms, but the persistence of A. butzleri exceeded that of E. coli at 5,15 , and $25^{\circ}$ C. Selective media for the isolation of Arcobacter spp., while sensitive enough to recover stressed A. butzleri cells, proved ineffective at selectively reducing background flora for quantification. At best, only a 10 -fold reduction in indigenous microflora was observed with antibiotic-containing selective media. Efforts were made to detect $A$. butzleri from raw sewage, poultry fecal matter, and poultry waterers comparing molecular methods and conventional plating on selective media. Cultural methods using selective plating media proved inferior to molecular methods. Molecular detection, though effective, also had limitations. Selective enrichment followed by nucleic acid purification may prove to be an important step in increasing sensitivity and reducing detection limits. 


\section{ACKNOWLEDGEMENTS}

Upon completion of this research project I would like to recognize several people. First I would like to thank my advisor, Dr. Gary Bissonnette. His guidance and knowledge were invaluable to me during the course of this project. Without his expertise and patience I'm certain this accomplishment would not have been possible.

I would also like to recognize my committee members, Dr. Alan Sexstone, Dr.

Robert Anderson, and Dr. P. Brett Kenney. Their help and support were greatly appreciated during my tenure at West Virginia University.

I would next like to thank Dr. Richard Gammon. A former undergraduate professor, he helped fuel my initial interest in microbiology. I certainly would not have chosen this profession without his guidance.

Finally I would like to thank my parents, Edward and Beverly. I could never imagine any two people giving more without ever asking anything in return. Without their love and support throughout the years none of my achievements would mean as much as they do today. 


\section{TABLE OF CONTENTS}

$\begin{array}{lll}\text { ABSTRACT } & \text { ii }\end{array}$

ACKNOWLEDGEMENTS

TABLE OF CONTENTS IV

LIST OF TABLES vi vi

LIST OF FIGURES viii

$\begin{array}{ll}\text { INTRODUCTION } & 1\end{array}$

LITERATURE REVIEW 2

Description of the genus $\quad 2$

Reservoirs $\quad 5$

$\begin{array}{ll}\text { Pathogenicity } & 7\end{array}$

$\begin{array}{ll}\text { Detection and identification } & 8\end{array}$

MATERIALS AND METHODS 13

Collection and processing of groundwater for in vitro microcosm studies 13

$\begin{array}{ll}\text { Preparation of test cultures } & 13\end{array}$

$\begin{array}{ll}\text { Preparation of microcosms } & 13\end{array}$

Evaluation of recovery conditions for detection of $A$. butzleri following exposure to groundwater

Comparative persistence of $A$. butzleri vs. E. coli in groundwater microcosms held at 5,15 , and $25^{\circ} \mathrm{C}$ and in several groundwater sources 14

Evaluation of selective recovery media to detect groundwater-stressed

A. butzleri

Recovery of $A$. butzleri from raw sewage 16

$\begin{array}{ll}\text { Identification of competing microflora on isolation plates } & 16\end{array}$

$\begin{array}{ll}\text { Survey of a poultry facility (feed water and feces) for A. butzleri } & 17\end{array}$

Molecular detection and spread plate isolation of $A$. butzleri from

raw sewage

21

Statistical analysis

$\begin{array}{ll}\text { RESULTS AND DISCUSSION } & 24\end{array}$

Recovery of groundwater stressed A. butzleri 24

Persistence of $A$. butzleri and E. coli during exposure to filter-sterilized groundwater at 5,15 , and $25^{\circ} \mathrm{C}$ 
Persistence of groundwater-stressed E. coli and A. butzleri at $25^{\circ} \mathrm{C}$ in several different groundwater sources

Recovery of groundwater-stressed $A$. butzleri cells in well water at $15^{\circ} \mathrm{C}$ and $25^{\circ} \mathrm{C}$ on several selective media

Use of COLCCDA medium for direct isolation $A$. butzleri from sewage

Isolation of $A$. butzleri from serially diluted and spiked raw sewage samples

Isolation of competing flora and partial characterization of isolates

Survey of chicken fecal matter and water from feeders: Spread

plating and multiplex PCR

Molecular detection and spread plate isolation of $A$. butzleri from raw sewage

Determination of $A$. butzleri optimum growth conditions and growth curve

Physical and chemical characterization of groundwater samples

LITERATURE CITED 


\section{LIST OF TABLES}

TABLE

PAGE

Table 1. PCR lane, sample, and source for fecal/water molecular detection.

19

Table 2. Primers used for multiplex PCR detection of $A$. butzleri from

environmental samples.

Table 3. PCR sample preparation for multiplex PCR detection of $A$. butzleri from sewage.

Table 4. Detection of $A$. butzleri after $24 \mathrm{~h}$ exposure to autoclaved groundwater at $15^{\circ} \mathrm{C}$.

Table 5. Detection of $A$. butzleri after $6 \mathrm{~d}$ exposure to autoclaved groundwater at $15^{\circ} \mathrm{C}$.

Table 6. Detection of $A$. butzleri after $9 \mathrm{~d}$ exposure to autoclaved groundwater at $15^{\circ} \mathrm{C}$.

Table 7. Decimal reduction times for E. coli and A. butzleri after exposure to filter-sterilized groundwater at three different incubation temperatures.

Table 8. Decimal reduction times for E. coli and A. butzleri after exposure to filter-sterilized groundwater sources at $15^{\circ} \mathrm{C}$.

Table 9. Sensitivity of selective media for detection of $A$. butzleri following exposure to filter-sterilized groundwater at $15^{\circ} \mathrm{C}$ for 4 and $9 \mathrm{~d}$.

Table 10. Sensitivity of selective media for detection of $A$. butzleri following exposure to filter-sterilized groundwater at $25^{\circ} \mathrm{C}$ for 24 and $48 \mathrm{~h}$.

Table 11. Plate counts of raw sewage under various incubation conditions

Table 12. Summary of sewage isolate characteristics

Table 13. Selective plate-count colony reduction for fecal and water samples from poultry.

Table 14. Colony counts for raw sewage samples incubated on nonselective R2A and selective COLCCDA.

Table 15. Percent $A$. butzleri-like colonies recovered after spread plating broths spiked with different levels of $A$. butzleri. 
Table 16. Chemical and physical analyses of groundwater used in microcosm studies. 


\section{LIST OF FIGURES}

Figure 1. Survival of $A$. butzleri at three different temperatures after exposure to filter-sterilized groundwater for $9 \mathrm{~d}$.

Figure 2. Survival of $E$. coli at three different temperatures after exposure to filter-sterilized groundwater for $9 \mathrm{~d}$.

Figure 3. Survival of $E$. coli in several filter-sterilized groundwater sources over a 24 -h period at $25^{\circ} \mathrm{C}$.

Figure 4. Survival of A. butzleri in several filter-sterilized groundwater sources over a 24 -h period at $25^{\circ} \mathrm{C}$.

Figure 5. Recovery of $A$. butzleri on several selective media after exposure to filter-sterilized groundwater at $15^{\circ} \mathrm{C}$ over a period of $9 \mathrm{~d}$.

Figure 6. Recovery of $A$. butzleri on several selective media after exposure to filter-sterilized groundwater at $25^{\circ} \mathrm{C}$ over a period of $48 \mathrm{~h}$.

Figure 7. Multiplex PCR results for chicken water and fecal samples.

Figure 8. Multiplex PCR results for sewage enrichment broths.

Figure 9. Absorbance at $540 \mathrm{~nm}$ for A. butzleri cultures grown in NB under different incubation conditions.

Figure 10. A. butzleri growth curve as determined in NB at $30^{\circ} \mathrm{C}$ during a $2 \mathrm{~d}$ period. 


\section{INTRODUCTION}

Designated a new taxon in 1991, the genus Arcobacter is considered by some public health officials as a likely causative agent of gastroenteritis in individuals consuming contaminated food or water. Grouped in the family Campylobacteraceae with Helicobacter and Campylobacter, Arcobacter spp. are gram-negative, aerotolerant rods, which demonstrate motility by a single, unsheathed, polar flagellum. Other than aerotolerance and ability to grow at temperatures as low as $15^{\circ} \mathrm{C}$, arcobacters are morphologically and physiologically similar to microaerophilic Campylobacter spp. Confirmed outbreaks of disease due to consumption of water or food containing arcobacters are now documented, however, relatively little is known about the survival, detection, and ecology of this genus. In particular, only a handful of selective and differential media exist to isolate Arcobacter spp. from clinical and environmental samples.

In the current study, efforts were focused on examining the survival and recovery of $A$. butzleri from the environment. The specific objectives were 1) to establish basic growth characteristics of $A$. butzleri including its optimum recovery conditions; 2) to examine the inactivation of $A$. butzleri in nutrient-deprived groundwater as compared to the classical indicator organism, E. coli, through controlled microcosm studies; 3) to determine the effect, if any, low-nutrient stress has on the sensitivity of $A$. butzleri to antibiotics contained in selective recovery media; and 4) to survey various potential arcobacter sources by viable plate count and multiplex PCR methodologies in an effort to evaluate the effectiveness of existing selective media to detect A. butzleri. 


\section{LITERATURE REVIEW}

Description of the genus. In 1976, Ellis et al. (10) isolated a small, curved, gram-negative rod, which had similar cultural and morphological characteristics to the genus Campylobacter. This aerotolerant, campylobacter-like bacterium was isolated from bovine and porcine aborted fetal tissues. Using semisolid Leptospira Ellinghausen McCullough-Johnson-Harris (EMJH) isolation medium, growth occurred at $30^{\circ} \mathrm{C}$ within $24 \mathrm{~h}$ under aerobic, microaerophilic, and anaerobic conditions. A lack of fermentative metabolism combined with a rapid darting movement via a single, polar, unsheathed flagellum (10) led all involved to believe that these bacteria were in fact a new species of Campylobacter. In addition, the guanine-cytosine composition of these bacteria was found to be 29 to $34 \mathrm{~mol}-\%$, well within the range of that calculated for Campylobacter (37). A new species, Campylobacter cryaerophila, was proposed by Neill et al. (37) in 1985 primarily due to its similarity to Campylobacter. These organisms are now officially members of the rRNA Superfamily IV of the Proteobacteria, Family Campylobacteraceae.

Despite possessing a number of characteristics suggesting close relatedness to the genus Campylobacter, these new isolates demonstrated other physiological traits that were uncharacteristic for campylobacters. The fact that this bacterium was aerotolerant gave rise to immediate suspicion since all Campylobacter species are microaerophilic and do not grow in the presence of full atmospheric oxygen. Also, the ability to grow rapidly on EMJH medium at $30^{\circ} \mathrm{C}$ was in contrast to all species of Campylobacter. Failure to grow on Campylobacter isolation media and failure to agglutinate with antisera to $C$.

fetus heat-stable $\mathrm{A}, \mathrm{B}$, and $\mathrm{C}$ antigens further gave rise to suspicion. 
As new media and isolation techniques became available, more information was generated so as to further differentiate this bacterium from Campylobacter. In 1988, Thompson et al. (54), using PCR restriction fragment length polymorphism (RFLP), found that $68 \%$ homology existed between this new bacterium and Campylobacter. They also found, however, an astounding 87\% homology within these new species. In 1991, Vandamme et al. (55) took these new data and along with their own work with immunotyping, SDS-PAGE, fatty acid analysis, and DNA-DNA hybridization proposed the genus name Arcobacter. Indeed, enough information existed to fully differentiate Arcobacter from Campylobacter. Arcobacter now occupies its own genus within the family Campylobacteraceae along with Helicobacter and Campylobacter. In 2001, On (38) proposed a dendogram representation of the relationship between the genera. Four species of Arcobacter are now recognized: A. cryaerophilus, A. butzleri, A. skirrowii, and A. nitrofigilis.

Members of the genus Arcobacter are described as non-spore forming, aerotolerant, gram-negative, curved, s-shaped or helical rods $(0.2$ to $0.9 \mu \mathrm{m} \times 0.5$ to 5.0 $\mu \mathrm{m})$, actively motile by a single, unsheathed, polar flagellum $(36,37,38,56)$. Although these bacteria grow from temperatures as low as $5^{\circ} \mathrm{C}$ to as high as $42^{\circ} \mathrm{C}$, optimal growth occurs under microaerophilic $\left(5 \% \mathrm{O}_{2}, 10 \% \mathrm{CO}_{2}, 85 \% \mathrm{~N}_{2}\right)$ conditions at $30^{\circ} \mathrm{C}(37)$. Arcobacters also demonstrate relatively good growth under anaerobic conditions at temperatures between $35^{\circ}$ and $37^{\circ} \mathrm{C}(58,59,60,61)$. The ability to grow in the presence of atmospheric oxygen at $15^{\circ}$ to $25^{\circ} \mathrm{C}$, however, clearly differentiates Arcobacter from Campylobacter $(54,55)$. These organisms are virtually metabolically inert, requiring enriched environments of blood or chocolate agar to grow. Usable energy sources are 
limited to either amino acids or citric acid cycle intermediates (22). Mansfield and Forsythe (29) summarized different metabolic reactions within the genus Arcobacter. It is clear from this report that biochemical differentiation among species is difficult.

Of the four recognized species, all but one has been isolated from animals and humans with a potential to be pathogenic. A. nitrofiglis, a nitrogen-fixing commensal of plants, is limited to the root environment Spartina, a salt-marsh inhabitant (32). In contrast to other species of Arcobacter, it has nitrogenase activity, is an obligate microaerophile, and grows in $4.0 \% \mathrm{NaCl}$. Also, a majority of these strains grow in $1.0 \%$ bile and have positive urease activity, suggesting an animal host reservoir. However, no association has been seen with this species and human or animal disease (58).

The other three species are found both as inhabitants and natural reservoirs of several animals, but also have been isolated from various environmental sources including wastewater, surface water, and groundwater $(21,42,47,48)$. Arcobacter cryaerophilus is by far the most diverse species of the group. It has further been divided into subgroups of hybridization group 1A and 1B based upon DNA-DNA, DNA-rRNA hybridization, SDS-PAGE, and fatty acid analysis. There are currently no phenotypic tests to differentiate the two groups. Although this species is relatively confined to animals, some cases of human enteritis have been associated with A. cryaerophilus. Arcobacter skirrowii was most recently designated a new species in 1992 by Vandamme et al. (56). This species has routinely been isolated from animal feces, porcine, ovine, and bovine abortions, and preputial fluid of bulls. Recent work by Welsey et al. $(58,59,60,61)$ and Skirrow $(46)$ has shown that this species is associated with human infection. 
The final recognized species, Arcobacter butzleri, is of major concern when dealing with human enteritis. This organism was the first aerotolerant Campylobacter associated with human infection and has been shown to be a primary human pathogen $(20,27,29,33,34,40,46,58,59,60,61,64)$. Routinely isolated from poultry, swine, nonhuman primates, horses, and cattle, A.butzleri also has been found in aborted cattle and spoiled meat. Generally, they are susceptible to chlorine and do not thrive in chlorinated water supplies $(21,42)$. They also demonstrate marked susceptibility to $0.5 \%, 1.0 \%$, and 2.0\% lactic and citric acids, $2 \%$ sodium lactate, and 500IU/ml nisin (39).

Reservoirs. Arcobacter spp. have been isolated from many different environments throughout the world, including Brazil, Canada, England, Germany, and the U.S. $(8,21,29,48)$. Arcobacters are natural inhabitants of ducks $(43,44)$, hogs, boars, and sows with reproductive problems $(8,49)$, aborted pig fetuses $(8,62)$, and a wide variety of cattle and livestock $(63,65)$. They have also been isolated from packaged chicken in supermarkets (2), various meat products $(2,4,5,7,28)$, sewage sludge (48), activated sludge (47), and from water and mussels of two brackish lakes near Messina, Italy (31).

In addition to these natural reservoirs, arcobacters have been isolated from patients with bacteremia, endocarditis, peritonitis, enteritis, and diarrhea $(11,20,64)$. A possible link between Arcobacter infections, arthritis, and Guillen-Barre Syndrome has been suggested (4). Meat products and water contamination have been cited as possible vehicles for transmission. Transmission has been studied in a drinking water reservoir in Germany, canal water in Thailand, river water in Italy, and well water in the U.S. $(58,60)$. Transmission of this bacterium has been reported in drinking water associated with 
travel, consumption of contaminated foods, and person-to-person contact (29). It must be noted that water related outbreaks of Arcobacter and Campylobacter are relatively rare in developed countries. Most, if not all, outbreaks result from breakdowns of water treatment plants or use of untreated (unchlorinated) water. This may account for the more widespread prevalence of these infections in those underdeveloped countries lacking a standard protocol for water treatment.

Several recent studies have documented the prevalence of arcobacters in drinking water facilities. During a two-year study of six drinking water plants in Germany, 147 campylobacter-like strains were isolated from nearly every stage of the drinking water treatment process (21). One hundred of these strains were categorized as A. butzleri, seventeen as A. butzleri-like, twenty-four as Arcobacter spp., and six as Campylobacter spp. Studies at a recent waterborne disease outbreak at a Girl Scout camp in the U.S. revealed an unusually high rate of survival in groundwater sources. Rice et al. (42) showed that Arcobacter spp. remained viable at temperatures of $5^{\circ} \mathrm{C}$ for up to $16 \mathrm{~d}$ with only a $0.5-\log _{10}$ reduction in population. Although relatively sensitive to chlorination, continuous chlorination must be observed to ensure proper disinfection (42).

Not only does this bacterium inhabit the water that we drink, it is also becoming a problem in the food we eat. Collins et al. (4) reported that $89 \%$ of ground pork samples taken from a slaughter plant in Iowa were positive for Arcobacter. Arcobacter butzleri was recovered from $96 \%$ of poultry carcasses obtained from five different processing plants in Canada (23). Detection of arcobacters in poultry and pork products is reportedly more common than that of red meat, although many cattle and livestock harbor this bacterium. Currently, radiation treatment is employed by the FDA to control 
Campylobacter spp. in pork products. Collins et al. (5) found that although Arcobacter spp. have a $\mathrm{D}_{10}$ value $1.4 \mathrm{x}$ higher than that of Campylobacter spp., both are very susceptible to radiation. A dose of $1.5 \mathrm{kGy}$ (a level within the accepted FDA regulation for poultry products) yields a 5.0-log-unit reduction of A. butzleri cells and a 7.0-log-unit reduction in $C$. jejuni cells, rendering meat products safe from these pathogens.

More recently, it has been found that Arcobacter spp. exist in much more complex ecological environments than previously thought. Telang et al. (50) isolated $A$. nitrofigilis from a nitrate-enriched oil production field in southwestern Saskatchewan, Canada. Originally thought of as a plant commensal, A. nitrofigilis now is believed to play a part in sulfur cycling in mixed cultures of sulfide-oxidizing and sulfate-reducing oil field bacteria. In addition, arcobacters have been found to inhabit underground crude oil storage cavities (57), Black Sea shelf sediments (52), and oil field brine (13)

Pathogenicity. Campylobacter and Arcobacter spp. are currently very common in the U.S. In fact, it is estimated that one in 100 people in the United States are infected with Campylobacter at any given time and over two million cases may occur annually $(23,35)$. This report may be grossly underestimated since hospitals do not routinely test for these bacteria. Even when technicians do make such an effort, they do not differentiate between Campylobacter and Arcobacter.

Although the mechanism of infection is not fully known, studies have been conducted to determine arcobacter virulence factors. Musmanno et al. (35) studied 18 isolates from river water samples for biotype, serogroup, and putative virulence characteristics. Cytotonic, cytotoxic, and cytolethal distending factors were determined using Vero and $\mathrm{CHO}$ cell lines. Adhesiveness and invasiveness were also studied. Most 
enteric bacteria cause disease by releasing certain verotoxins or Shiga toxins I and II during metabolism. Of the18 strains studied, all but one-showed characteristics of cytotoxicity causing epithelial cells to elongate and lyse. Surprisingly, only one of the isolates displayed adhesiveness and none were found to be invasive. Although this study brings some light to the mechanism of infectivity of these bacteria, more work is needed.

Several cases of human associated bacteremia have been documented. Yan et al. (64) described a 60-year old man with liver cirrhosis who presented with high fever and esophageal variceal bleeding. Blood cultures yielded campylobacter-like organisms but upon sequence analysis of the $16 \mathrm{~S}$ rRNA, the isolate was identified as $A$. butzleri. Similarly, Hsueh et al. (20) reported a case of bacteremia in a 70-year old woman. Again, after extensive biochemical analysis and antimicrobial susceptibility testing, the organism was identified as $A$. cryaerophilus. More often than not, though, these bacteria are limited to enteric invasion and gastrointestinal problems. Higgins et al. (17) described a case of Arcobacter butzleri isolated from a diarrheic non-human primate. Some species, however, have shown a tendency to invade other organs in some animals. A. cryaerophilus, for example, has been recovered from fetal livers, kidneys, and thoracic fluid and cattle uteruses, oviducts, and placentas $(2,8,28,43,44,49,62,63)$.

Detection and identification. In 1977, Ellis et al. (10) discovered a new species of Campylobacter growing in EMJH agar, a medium originally used for the isolation of Leptospira spp. These bacteria were found to be aerotolerant, with temperature tolerances much lower than those of Campylobacter. For years, no specific medium was available to isolate and differentiate these bacteria from Campylobacter spp. To detect arcobacters from the environment, samples were inoculated onto semisolid EMJH P-80 
(Ellinghausen-McCullough-Johnson-Harris Polysorbate-80) supplemented with $100 \mu \mathrm{g} / \mathrm{ml}$ of 5 -fluorouracil and incubated under microaerophilic conditions at $25^{\circ} \mathrm{C}$ for up to 4 days. Then, pure cultures were obtained by streaking colonies onto blood or chocolate agar and incubating plates aerobically an additional 2-3 days (10). Too much time elapsed between original sampling and final isolation and identification. In addition, simple biochemical tests were difficult to perform because of the limited metabolic activity of the arcobacters. Eventually, certain metabolic activities were studied, and by way of catalase activity, nitrate reduction, and sensitivity to certain antibiotics, researchers were better able to differentiate Arcobacter from other similar bacteria $(16,18)$.

Marshall et al. (30) refined a rather practical and successful method of identification by PCR-RFLP of the 16s rRNA gene of Arcobacter. Using two newly developed primers, they successfully categorized 158 isolates of Helicobacter, Arcobacter, and Campylobacter. Although this method of detection and identification is rapid and successful, it is relatively impractical in the clinical setting.

"Unique RFLP fingerprints obtained from unidentified strains could suggest the presence of new species. However, a greater number of isolates will have to be tested to assess the potential interspecies variability of this method. Furthermore, the method would have to be expanded to include fingerprints from other known species before the technique could reliably be used for the above mentioned purpose." (Marshall et al. 1999)

Harmon and Wesley (15) attempted to develop a more practical multiplex PCR gel-electrophoretic technique using dual sets of primers to detect the genus Arcobacter, and also to differentiate between the various species. Their method, however, failed to distinguish between different species of Arcobacter furthering the need for more research. Finally, in 1997, Harmon and Wesley (14), using a new set of primers designed 
to detect the 23S rRNA of Arcobacter butzleri, developed a multiplex PCR method to differentiate $A$. butzleri from other arcobacters. Houf et al. (19) later developed a multiplex PCR technique to simultaneously detect and differentiate all four Arcobacter species.

The effectiveness of these techniques, however, is limited. Molecular techniques are reliable only in assessing the presence and/or absence of an organism. Simply detecting bacterial DNA from an organism in a host reservoir is not enough. To effectively study an organism of disease, the viable organism itself must be isolated from the host. Studying the pathogenicity of the organism may help to lead to significant deterrents to its proliferation.

Arcobacters grow poorly on conventional media, requiring addition of blood or chocolate due to their fastidious nature (23). Once isolated on blood agar, arcobacters appear as white or gray, round colonies, 2.0 to $4.0 \mathrm{~mm}$ in diameter (4). Methods for isolation involve a filtration step wherein an enrichment culture of carcass washings or caeca contents is passed through a $0.45 \mu \mathrm{m}$ or $0.65 \mu \mathrm{m}$ membrane filter. This method has been suggested and used in various forms for isolation since arcobacters will pass though a $0.45 \mu \mathrm{m}$ filter (43). Again, however, this method will not allow the quantification of Arcobacter spp. since all of the cells may not pass through the filter.

Collins et al. (4) developed a plating technique for detection of Arcobacter spp. in ground pork intended for consumption. Initial efforts using Vandamme's charcoal and blood agar (55) failed to provide the selective qualities needed to enumerate the bacteria from meats. Subsequently, modifications were made to Cefsulodin-Irgasin-Novobiocin (CIN) agar by adding sodium L-glutamate to enhance growth, various salts to control ion 
concentrations and 5-florouracil to inhibit other gram-negative and gram-positive bacteria to enhance selectivity. Overall, the modified CIN medium enabled selective detection of Arcobacter spp. in $78.5 \%$ of 149 samples of ground pork, compared to only $50 \%$ detection with no selectivity on BHI blood agar (4). These results were promising, but due to the vast number of antibiotics that arcobacters are susceptible and resistant to, different types and concentrations of antibiotics may select for a completely different population of Arcobacter (4).

In 1998, Oxoid developed and marketed an arcobacter specific enrichment medium (AM). This medium was tested by Atabay et al. (3) against Preston Broth, Lab $\mathrm{M}$ broth (both campylobacter enrichment broths), and arcobacter basal medium (a control without selective supplements). None of the Campylobacter species were able to grow in the AM medium, whereas the Arcobacter spp. were recovered with great specificity.

Recently, several more attempts have been made to develop selective and differential media alike. Johnson and Murano (23) used various additives of charcoal, pyruvate, bile salts, sheep blood, glutamic acid, thioglycotic acid, and antibiotics to develop six enrichment broths for the species specific isolation and differentiation between Arcobacter spp. with fairly successful results. In addition to superior growth characteristics, a deep red color was exhibited by the Arcobacter spp., differentiating them from other bacteria. Johnson and Murano (22) also tested the productivity of three different protocols for the isolation of Arcobacter from poultry. They reported effective isolation of arcobacters using their newly developed procedure as well as the procedures developed by Colins et al. (4) and de Boer et al. (7). 
Corry and Atabay (6) tested a set of selective media using cefoperazone, amphotericin, and teicoplanin (CAT) and cefoperazone deoxycholate agar (CCDA) selective supplements. They found that the CAT supplement supported the growth of a wider variety of Campylobacter and Arcobacter species than CCDA. This may be due to the lower levels of cefoperazone incorporated into the CAT supplement. CCDA contains a higher level of cefoperazone to further enhance the specificity to fewer Arcobacter and Campylobacter species.

Several other studies have been done using EMJH, CIN, AM, CVA (cephalothin vancomycin and amphotericin B) and other media with mixed results $(3,4,6,7,22,23)$. de Boer et al. (7) attempted to develop a selective medium for the isolation of Arcobacter spp. from meats, using a combination of piperacillin, cefoperazone, and trimethoprim in brucella broth powder with relatively good success. Recent work by Harrab et al. (16) attempted to characterize Arcobacter isolates based upon biochemical tests, antimicrobial resistance patterns, and plasmid analysis. Plasmid analysis proved nondiscriminatory with detection of small plasmids of up to $5 \mathrm{kbp}$ in only 21 of 89 Arcobacter butzleri isolates. Biochemical analysis and antimicrobial susceptibility analysis proved the most successful ways to differentiate isolates. Houf et al. (18) developed antimicrobial susceptibility patterns for all four Arcobacter species using 12 different antibiotics. These results may substantially improve the ability of existing media to isolate and quantify Arcobacter spp. within natural environments. 


\section{MATERIALS AND METHODS}

\section{Collection and processing of groundwater for in vitro microcosm studies.}

Approximately 51 of ground water was collected in sterile plastic Nalgene containers from four private wells in northern West Virginia: one from Monongalia County (S), and three from Preston County (VP, P1, and P2). All wells are private-use drilled wells. A portion of each water sample was sterilized by autoclaving or membrane filtration $(0.22 \mu \mathrm{m}$ pore size filters). Both raw and sterilized water were stored in 11 portions at $5^{\circ} \mathrm{C}$ until used. Raw water sample (S) was analyzed for heterotrophic plate count (HPC) bacteria via the membrane filtration method (1).

Preparation of test cultures. Arcobacter butzleri ATCC \# 49616 and Escherichia coli ATCC \# 23559, obtained from the American Type Culture Collection (Mannassas, VA.), were used as test organisms. For in vitro survival studies, E. coli was inoculated into $100 \mathrm{ml}$ of NB and incubated under static, aerobic conditions at $37^{\circ} \mathrm{C}$.

After $24 \mathrm{~h}$ incubation, this culture was used to inoculate another $100 \mathrm{ml}$ of NB and incubated under identical conditions used to prepare the primary culture. Following $24 \mathrm{~h}$ of incubation, $10 \mathrm{ml}$ of culture was centrifuged at $5090 \mathrm{x} \mathrm{g}$ for $10 \mathrm{~min}$ at $5^{\circ} \mathrm{C}$. The pellet was resuspended in $0.1 \%$ peptone and washed two times under the same conditions. The final pellet was resuspended in $10 \mathrm{ml}$ of sterile water of the same type to be used in the in vitro survival studies. The same procedure was used to prepare the $A$. butzleri suspension except that the culture was incubated at $30^{\circ} \mathrm{C}$ for 24 to $48 \mathrm{~h}$.

Preparation of microcosms. One hundred $\mathrm{ml}$ of autoclaved or filter-sterilized groundwater was aseptically added to sterile $500-\mathrm{ml}$ flasks and covered with cotton plugs. Flasks were equilibrated for $24 \mathrm{~h}$ at the appropriate temperature for the respective 
survival experiments prior to inoculation with the E. coli or A. butzleri preparations as previously described. Inoculum size was adjusted to achieve an initial (0-time) density of approximately $1.0 \times 10^{6} \mathrm{CFU} / \mathrm{ml}$ in the microcosms.

\section{Evaluation of recovery conditions for detection of $\boldsymbol{A}$. butzleri following}

exposure to groundwater. In order to determine the optimal conditions for recovery of groundwater-stressed $A$. butzleri, several experiments were conducted wherein different recovery media and oxygen incubation conditions were examined. In each experiment, washed cells of $A$. butzleri were added to $100 \mathrm{ml}$ of sterilized groundwater and incubated at $15^{\circ} \mathrm{C}$. Aliquots were removed immediately $(0-\mathrm{h})$ and at subsequent time intervals (up to 9 days depending upon the particular experiment) for determination of survivors using the spread plate technique (1). Media used included: nutrient agar (NA), trypticase soy agar (TSA), brain heart infusion agar (BHI), TSA containing 5\% sheep red blood cells (TSABL), and BHI containing 5\% sheep red blood cells (BHIBL). Plates were incubated under aerobic or microaerophilic conditions. After $48 \mathrm{~h}$ of incubation at $30^{\circ} \mathrm{C}$, colonies were counted. In each case only one flask was prepared and sampled in triplicate.

Comparative persistence of $A$. butzleri vs $E$. coli in groundwater microcosms held at 5, 15, and $25^{\circ} \mathrm{C}$ and in several groundwater sources. Duplicate $100 \mathrm{ml}$ groundwater microcosms were inoculated with either A. butzleri or E. coli. Microcosm sets (two at each temperature) were incubated at 5,15 , and $25^{\circ} \mathrm{C}$. Periodically $(0$-h, 1, 4, and 9 d) samples were removed from the microcosms to determine survivors. Surviving A. butzleri cells were enumerated on TSABL incubated aerobically at $30^{\circ} \mathrm{C}$ for $48 \mathrm{~h}$, whereas E. coli populations were determined on NA incubated at $35^{\circ} \mathrm{C}$ for $48 \mathrm{~h}$. 
Next, sterilized microcosms were prepared using four different groundwater sources in order to evaluate the response of both organisms to a variety of groundwater sources. Only one flask was prepared for each groundwater source and sampled in triplicate. Washed A. butzleri or E. coli cells were added to the microcosms and incubated at $25^{\circ} \mathrm{C}$. Surviving populations were monitored over approximately 2 days of exposure as previously described.

\section{Evaluation of selective recovery media to detect groundwater-stressed $A$.}

butzleri. The sensitivity of several selective media for recovery of groundwater-stressed A. butzleri was examined. Duplicate microcosms (2 at each temperature) were incubated at 15 and $25^{\circ} \mathrm{C}$. Survivors were monitored for several days using different media. Each flask was sampled in triplicate giving each data point a total of six individual plate counts.

TSABL was again used as a control and compared for recovery efficiency with two different blood-based agars in combination with two sets of antibiotics. Columbia blood agar base (Oxoid) was prepared with the aseptic addition of 5\% defibrinated sheep blood (Cleveland Scientific). A commercially prepared combination (Oxoid) of the antibiotics cefoperazone, amphotericin, and teicoplanin (CAT) or cefoperazone and amphotericin (CCDA) was added to the Columbia blood agar to yield media designated COLCAT and COLCCDA, respectively. The COLCAT medium was designed for isolation of all species of Arcobacter, whereas COLCCDA is reportedly specific for the isolation of $A$. butzleri (6). In addition, Arcobacter broth (ABM) (Oxoid) supplemented with $10 \%$ purified agar (Oxoid) and 5\% defibrinated sheep blood was used as a second blood-based culture medium. Supplements were added to produce selective media 
designated $\mathrm{ABMCAT}$ and $\mathrm{ABMCCDA}$. Also, a nonselective medium (no antibiotics) containing Arcobacter broth, agar, and blood (ABMCONT) was used to monitor survivors. Following aerobic incubation at $30^{\circ} \mathrm{C}$ for $48 \mathrm{~h}$, colonies were counted.

Recovery of $A$. butzleri from raw sewage. A sample of raw sewage was collected from the Morgantown Wastewater Treatment Plant. A portion of sewage was sterilized by autoclaving. A suspension of A. butzleri was added to $200 \mathrm{ml}$ of nonsterilized and autoclaved sewage to achieve a final concentration of approximately 5.0x10 $0^{4} \mathrm{CFU} / \mathrm{ml}$. A third flask containing $200 \mathrm{ml}$ of raw sewage was not inoculated with the test organism. Each flask was sampled and examined by the spread plate technique using COLCCDA agar. Plates were incubated as follows: $15^{\circ} \mathrm{C} /$ aerobic; $15^{\circ} \mathrm{C} /$ microaerophilic; and $30^{\circ} \mathrm{C} /$ microaerophilic for $4 \mathrm{~d}$. A total heterotrophic plate count (HPC) was preformed on the raw sewage using R2A agar incubated at $28^{\circ} \mathrm{C}$ for 5 days.

A second sample of raw sewage was obtained. Full-strength, 1:10, and 1:100 diluted sewage aliquots were prepared and spiked with A. butzleri to achieve an approximate final concentration of $5.0 \times 10^{4} \mathrm{CFU} / \mathrm{ml}$. Samples were removed from each of the three flasks and plated onto COLCCDA. Following incubation for 4 days at $15^{\circ} \mathrm{C}$ under microaerophilic conditions, colonies were counted.

Identification of competing microflora on isolation plates. After incubation, each plate was observed for dominant colony types. The most frequently occurring types were picked, isolated, and streaked onto BHI slants and stored at $5^{\circ} \mathrm{C}$. Basic isolate characteristics (gram stain, morphology, growth in NA, oxygen requirements, mannitol, glucose, and lactose fermentation, phenylalanine deamination, indole production, methyl 
red, Voges Proskauer, citrate utilization, urease activity, motility, $\mathrm{H}_{2} \mathrm{~S}$ production, starch hydrolysis, catalase production, oxidase production, and caesein hydrolysis) were observed and recorded. After obtaining results, isolates were placed into 9 categories based upon biochemical characteristics

\section{Survey of a poultry facility (feed water and feces) for A.butzleri. Several}

environmental samples were obtained from the poultry facility at the West Virginia University farm on Stewartstown Road in Morgantown, WV. Three water samples from chicken feeders and four fecal samples were collected from a combination of hens, roosters, chickens, and turkeys. Fecal samples were collected in plastic bags with sterile gloves by hand, and water samples were collected in sterile $200 \mathrm{ml}$ plastic bottles. All samples were collected and placed on ice during transport to the laboratory and processed within three hours of collection. One $\mathrm{g}$ of fecal matter from each of the four samples was serially diluted in $9.0 \mathrm{ml}$ peptone $(0.1 \%)$ blanks. Appropriate dilutions were spread plated in triplicate onto COLCCDA. Plates were incubated at $15^{\circ} \mathrm{C}$ under microaerophilic conditions for 4 days. A positive control was prepared by adding approximately $5.0 \times 10^{4} \mathrm{CFU} / \mathrm{ml}$ A. butzleri to one of the fecal suspensions before plating. Feeder water samples were analyzed by surface plating $0.1 \mathrm{ml}$ of water on COLCCDA agar in triplicate. Larger volumes of water $(1 \mathrm{ml}$ and $10 \mathrm{ml})$ were processed by membrane filtration $(0.22 \mu \mathrm{m}$ filter $)$. The filters were placed onto COLCCDA agar. A positive control was established by spiking one of the water samples with $5.0 \times 10^{4}$ $\mathrm{CFU} / \mathrm{ml}$ of $A$. butzleri before direct plating and plating of filtered volumes $(1 \mathrm{ml}$ and 10 ml). Each fecal and water sample was also subjected to an HPC on R2A aerobically at $28^{\circ} \mathrm{C}$ for $5 \mathrm{~d}$. 
In addition to viable plate counts, enrichments for Multiplex PCR were made using Arcobacter Broth (Oxoid) and CAT selective supplement (Oxoid). One g of fecal matter was placed into $9.0 \mathrm{ml}$ of enrichment broth. The tube was vortexed for $2 \mathrm{~min}$, left to sit for $2 \mathrm{~min}$, and vortexed again for $2 \mathrm{~min}$ to ensure even distribution of fecal matter. The same procedure was used for each of the four samples. A positive control was achieved by inoculating one of the fecal samples with approximately $5.0 \times 10^{4} \mathrm{CFU} / \mathrm{ml} A$. butzleri. For each of the three water samples, another $10 \mathrm{ml}$ sample was filtered and the filters were placed into $10 \mathrm{ml}$ of the enrichment broth for subsequent multiplex PCR analysis. Again, a positive control was established by spiking one of the enrichments with $5.0 \times 10^{4} \mathrm{CFU} / \mathrm{ml}$ A. butzleri. Table 1 shows the relationship between sample, source, and PCR lane for all samples. All plates were placed at $15^{\circ} \mathrm{C}$ for $4 \mathrm{~d}$ under microaerophilic conditions.

After 5 days of enrichment at $15^{\circ} \mathrm{C}$ under microaerophilic conditions, $2.0 \mu 1$ of each sample was removed and placed into a sterile microfuge tube for PCR sample preparation. Two sets of primers were obtained from Invitogen Life Technologies (Table 2). PCR amplification was preformed on a final $50 \mu 1$ mixture containing: $31.5 \mu 1$ distilled/deionized water, $5 \mu \mathrm{l}$ x buffer $(50 \mathrm{mM} \mathrm{KCl}, 10 \mathrm{mM}$ Tris-HCl $\mathrm{pH}$ 9.0, 0.1\% (vol./vol.) Triton X-100), $1.5 \mathrm{mM} \mathrm{MgCl} 2,1 \mu \mathrm{dNTP}$ (mixed from $10 \mathrm{mM}$ each stock), $2.5 \mu 1$ of each primer (from $20 \mathrm{pmol} / \mu 1$ stock), $0.5 \mu 1$ Taq DNA polymerase (from 5 units $/ \mu 1$ stock), and $2 \mu 1$ enrichment culture. Samples were subjected to a routine PCR cycle (MJ research PTC 100 Watertown, MA) consisting of an initial denaturation step $\left(94^{\circ} \mathrm{C}\right.$ for $\left.4 \mathrm{~min}\right)$, followed by 30 amplification cycles. Each cycle consisted of $1 \mathrm{~min}$ at $94^{\circ} \mathrm{C}$ (denaturation), 1 min at $56^{\circ} \mathrm{C}$ (primer annealing), and 1.5 min at $72^{\circ} \mathrm{C}$ (primer 
TABLE 1. PCR lane, sample, and source of PCR samples for fecal/water molecular detection

\begin{tabular}{ccl}
\hline PCR lane & Sample $^{\mathrm{a}}$ & \multicolumn{1}{c}{ Source/contents } \\
\hline 1 & - & bp Standard \\
2 & Fecal 1 & Rooster/hen mixed floor pen \\
3 & Fecal 2 & Rooster floor pen \\
4 & Fecal 3 & Individual stacked hen pens \\
5 & Fecal 4 & Turkey in grouped floor pens \\
6 & Fecal 4 & Spiked with $10^{4}$ CFU/ml A. butzleri \\
7 & Water 1 & Turkey water feeders \\
8 & Water 2 & Rooster water main line \\
9 & Water 3 & Main water line of rooster/hen mixed pen \\
10 & Water 3 & Spiked with 10 $0^{4}$ CFU/ml A. butzleri \\
11 & - & Sterile enrichment broth (negative control) \\
12 & - & Pure A. butzleri culture in enrichment broth \\
\hline
\end{tabular}

${ }^{\mathrm{a}}$ All fecal samples consisted of $1.0 \mathrm{~g}$ fecal matter in $9.0 \mathrm{ml}$ enrichment broth incubated at $15^{\circ} \mathrm{C}$ for $4 \mathrm{~d}$ microaerophilically. All water samples consisted of $10.0 \mathrm{ml}$ water filtered through a $0.22 \mu \mathrm{m}$ filter and placed into $10 \mathrm{ml}$ enrichment broth. 
TABLE 2. Primers used for multiplex PCR detection of $A$. butzleri from environmental samples ${ }^{\mathrm{a}}$

\begin{tabular}{llllll}
\hline Set & Target & Specificity & $\begin{array}{l}\text { Product } \\
\text { Size (bp) }\end{array}$ & $\begin{array}{l}\text { Primer } \\
\text { Designation }\end{array}$ & Nucleotide Sequence \\
\hline I & $\begin{array}{l}\text { 16S rRNA gene } \\
\text { (Harmon and Wesley, }\end{array}$ & Arcobacter & 1223 & Arco I & AGA GAT TAG CCT GTA TTG TAT C \\
& 1996) & & Arco II & TAG CAT CCC CGC TTC GAA TGA \\
& & & & \\
\hline II & 23S r RNA gene & Arcobacter & 686 & Arco 2 & TTC GCT TGC GCT GAC AT \\
& (Bastyns et al., 1995) & butzleri & & Butz & CTA TTC AGC GTA GAA GAT G \\
\hline
\end{tabular}

${ }^{\mathrm{a}}$ Table adapted from Harmon and Wesley, 1997. 
extension). PCR reaction products were detected by electrophoretic separation (100V for approx. 2 h) on $1.0 \%$ agarose gel in a horizontal gel bed (Life Technologies model H5 horizontal gel bed Gaithersburg, MD). The gel was run in $0.5 \mathrm{x}$ TBE (45mM Tris-borate, 1.0mM EDTA), and the PCR product was stained with ethidium bromide at $500 \mathrm{ng} / \mathrm{ml}$. A 50-bp DNA ladder (GIBCO BRL) was used for a standard.

\section{Molecular detection and spread plate isolation of $\boldsymbol{A}$. butzleri from raw}

sewage. A sample of raw sewage was obtained from the sewage treatment plant as before. The sample was immediately subject to an HPC as previously described.

Additionally, a sample was serially diluted and spread plated onto COLCCDA plates and incubated at $15^{\circ} \mathrm{C}$ under microaerophilic conditions for $4 \mathrm{~d}$. Next a sewage sample was spiked with approximately $10^{4} \mathrm{CFU} / \mathrm{ml}$ A. butzleri, serially diluted, and spread plated onto COLCCDA plates incubated as before.

Sewage enrichments were next prepared from remaining sewage for multiplex PCR analysis. Enrichments consisted of $9.0 \mathrm{ml}$ of ABMCAT enrichment broth, $1.0 \mathrm{ml}$ of raw sewage, and a proportional 10 -fold spike of $A$. butzleri incubated for $4 \mathrm{~d}$ at $15^{\circ} \mathrm{C}$ under microaerophilic conditions. In addition to spiked enrichments, several other samples were processed for PCR detection (Table 3).

Samples 1, 2 and 5-10 were prepared previous to enrichment and frozen at $-20^{\circ} \mathrm{C}$ until needed for multiplex PCR. The remaining samples were enriched at $15^{\circ} \mathrm{C}$ for 4 days under microaerophilic conditions. After enrichment, previously frozen samples were thawed and all samples were processed and prepared as before for multiplex PCR. Statistical Analysis. Statistical analysis was preformed using Microsoft Excel '97 and SAS release 8.00. For experiments involving optimum recovery of stressed A. butzleri 
TABLE 3. PCR sample preparation for multiplex PCR detection of $A$. butzleri from raw sewage

\begin{tabular}{cl}
\hline PCR well & \multicolumn{1}{c}{ Contents $^{\mathrm{a}}$} \\
\hline $1^{\mathrm{b}}$ & Raw Sewage Sample \\
$2^{\mathrm{b}}$ & Raw Sewage $+10^{4}$ CFU/ml spike \\
$3^{\mathrm{c}}$ & Raw Sewage in enrichment broth \\
$4^{\mathrm{c}}$ & Raw Sewage Sample \\
$5^{\mathrm{b}}$ & Enrichment $+10^{1}$ spike \\
$6^{\mathrm{b}}$ & Enrichment $+10^{2}$ spike \\
$7^{\mathrm{b}}$ & Enrichment $+10^{3}$ spike \\
$8^{\mathrm{b}}$ & Enrichment $+10^{4}$ spike \\
$9^{\mathrm{b}}$ & Enrichment $+10^{5}$ spike \\
$10^{\mathrm{b}}$ & Enrichment $+10^{6}$ spike \\
$11^{\mathrm{c}}$ & Enrichment $+10^{1}$ spike \\
$12^{\mathrm{c}}$ & Enrichment $+10^{2}$ spike \\
$13^{\mathrm{c}}$ & Enrichment $+10^{3}$ spike \\
$14^{\mathrm{c}}$ & Enrichment $+10^{4}$ spike \\
$15^{\mathrm{c}}$ & Enrichment $+10^{5}$ spike \\
$16^{\mathrm{c}}$ & Enrichment $+10^{6}$ spike \\
$17^{\mathrm{c}}$ & A. butzleri in enrichment broth \\
18 & bp Standard \\
\hline
\end{tabular}

${ }^{a}$ Enrichments consisted of $9.0 \mathrm{ml}$ ABMCAT enrichment broth, $1.0 \mathrm{ml}$ of raw sewage, and corresponding spike level.

${ }^{\mathrm{b}}$ Samples analyzed before $15^{\circ} \mathrm{C}, 4 \mathrm{~d}$ microaerophilic incubation.

${ }^{\mathrm{c}}$ Samples analyzed after $15^{\circ} \mathrm{C}, 4 \mathrm{~d}$ microaerophilic incubation. 
cells, t-tests were preformed on individual means for direct comparisons. For survival studies at different temperatures and in different groundwater sources, regression lines were generated from data points and used in the following equation for D-value determination.

$\mathrm{D}$-value $=1 /$-(slope of reg. line $)$

Percent injury was calculated by the following equation:

$\%$ injury $=(\mathrm{CFU}$ on nonselective medium $-\mathrm{CFU}$ on selective medium $) \times 100$ $\mathrm{CFU}$ on nonselective medium

For experiments involving recovery on selective media, the Proc GLM procedure was used to perform ANOVA on individual media recovery data. Mean recovery values were generated and compared for statistical differences between media. 


\section{RESULTS \& DISCUSSION}

As more and more information becomes available, it is evident that Arcobacter species are becoming a more significant public health problem. Recent isolations of arcobacters from livestock, poultry, and humans give rise to a legitimate cause for concern for its evolution as a new and emerging pathogen $(2,4,8,10,11,17,20,28,43,44$, $46,49,63,64)$. At the same time, relatively little information is available concerning the survival and detection of Arcobacter spp. in natural environments such as groundwater. Most work has been focused on Campylobacter spp. and Salmonella spp. Currently, there are no standard protocols for the isolation and identification of Arcobacter spp. Health care facilities do not routinely test for this bacterium. Due to a lack of metabolic activity and fastidious growth of arcobacters, isolation, and particularly quantification, is extremely difficult.

Recovery of groundwater-stressed $\boldsymbol{A}$. butzleri. Several media were evaluated for sensitivity in detection of $A$. butzleri following prolonged exposure to groundwater. Initial experiments compared the recovery efficiency of NA, TSA, BHI, and TSABL (Table 4). Each of these media is commercially available and is generally recognized as nutrient-rich growth media. Recovery of groundwater exposed cells was significantly better $(\mathrm{p}<0.05)$ on BHI and TSABL than on NA or TSA. Given that Arcobacter spp. are fastidious organisms, the enhanced recovery on TSABL and BHI was expected. NA and TSA without blood were subsequently eliminated from further study as they were inferior in recovery efficiency.

Since arcobacters are considered aerotolerant, the efficiency in recovery on TSABL and BHIBL was next examined under aerobic and microaerophilic conditions 
TABLE 4. Detection of $A$. butzleri after $24 \mathrm{~h}$ exposure to autoclaved groundwater at $15^{\circ} \mathrm{C}$

\begin{tabular}{cc}
\hline Medium & Survivors detected $^{\mathrm{a}}$ \\
\hline TSABL & $3.3 \mathrm{a}$ \\
BHI & $3.1 \mathrm{a}$ \\
NA & $2.7 \mathrm{~b}$ \\
TSA & $1.8 \mathrm{c}$ \\
\hline
\end{tabular}

${ }^{a} \log$ CFU/ml (arithmetic mean of triplicate plate counts) following aerobic incubation at $30^{\circ} \mathrm{C}$, for $2 \mathrm{~d}$. Values with different letters indicate significant differences in recovery at $\mathrm{p}<0.05$. 
(Table 5). After $6 \mathrm{~d}$ exposure to sterile groundwater, TSABL proved statistically

$(\mathrm{p}<0.05)$ superior to BHIBL, both under aerobic and microaerophilic conditions. BHIBL was therefore eliminated from further study.

Finally, Table 6 shows the recovery of groundwater exposed A. butzleri cells for TSABL incubated aerobically vs. TSABL incubated microaerophilically. After nine days, no significant difference $(\mathrm{p}>0.05)$ in recovery between the two sets of conditions was seen. Collectively, the results from these preliminary experiments indicate that there was no advantage to using microaerophilic incubation for the recovery of groundwaterstressed $A$. butzleri, provided that blood was added to the recovery medium (e.g., TSABL). Aside from the cost of microaerophilic incubation, aerobic incubation greatly increases ease at which experiments can be conducted. These results, however, conflict with some reports that arcobacters often do not demonstrate prolific growth aerobically upon initial isolation from animal sources (7). It is well documented, however, that the addition of blood to various media may result in increased recovery of stressed cells. Johnson and Murano (23) reported that the addition of blood or charcoal to a medium might bind toxic oxygen compounds within the growth medium, thus affording some protection to microaerophilic organisms such as Arcobacter and Campylobacter. This may explain that while TSA is a rich growth medium, recovery of stressed cells was inferior to that of TSABL. It also would explain the fact that no significant differences in recovery were seen with TSABL whether incubated aerobically or microaerophilically.

\section{Persistence of $\boldsymbol{A}$. butzleri and $\boldsymbol{E}$. coli during exposure to filter-sterilized}

groundwater at 5,15 , and $25^{\circ} \mathbf{C}$. Since aerobic incubation on TSABL at $30^{\circ} \mathrm{C}$ proved efficient in recovery of stressed arcobacter cells in the prior experiments, these recovery 
TABLE 5. Detection of $A$. butzleri after $6 \mathrm{~d}$ exposure to autoclaved groundwater at $15^{\circ} \mathrm{C}$

\begin{tabular}{llc}
\hline Medium & Incubation conditions & Survivors detected $^{\mathrm{a}}$ \\
\hline TSABL & Microaerophilic & $4.94 \mathrm{a}$ \\
TSABL & Aerobic & $4.81 \mathrm{~b}$ \\
$\mathrm{BHIBL}$ & Microaerophilic & $4.83 \mathrm{~b}$ \\
BHIBL & Aerobic & $4.59 \mathrm{c}$ \\
\hline \multicolumn{2}{c}{${ }^{\mathrm{a}} \mathrm{Log} \mathrm{CFU} / \mathrm{ml}$ (arithmetic mean of triplicate plate counts) following } \\
incubation at $30^{\circ} \mathrm{C}$ for $2 \mathrm{~d}$. Values with different letters indicate \\
significant differences at $\mathrm{p}<0.05$.
\end{tabular}


TABLE 6. Detection of $A$. butzleri after $9 \mathrm{~d}$ exposure to autoclaved groundwater at $15^{\circ} \mathrm{C}$

\begin{tabular}{clc}
\hline Medium & Incubation condition & Survivors detected $^{\mathrm{a}}$ \\
\hline TSABL & Aerobic & $6.7 \mathrm{a}$ \\
$\mathrm{TSABL}$ & Microaerophilic & $6.7 \mathrm{a}$ \\
\hline \multicolumn{2}{c}{$\mathrm{Log} \mathrm{CFU} / \mathrm{ml}$ (arithmetic mean of triplicate plate counts) following } \\
incubation at $30^{\circ} \mathrm{C}$ for $2 \mathrm{~d}$. Values with different letters indicate \\
significant differences at $\mathrm{p}<0.05$.
\end{tabular}


conditions were used to monitor the survival of $A$. butzleri (Figure 1) in groundwater held at three different temperatures as compared to the classical sanitary-indicator organism, E. coli (Figure 2). Survival of both organisms was inversely related to temperature as reflected by decreased survival as the stress temperatures increased from 5 to $25^{\circ} \mathrm{C}$. At $5^{\circ} \mathrm{C}$, there was no change in the population density of $A$. butzleri during the nine days of exposure. There was an approximate one-log reduction in survivors at $15^{\circ} \mathrm{C}$, whereas rapid die-off occurred at $25^{\circ} \mathrm{C}$ as demonstrated by failure to detect any survivors within 4 days of stress. These results compare favorably to a previous study by Rice et al. (42) who reported a $0.5 \log$ reduction in $A$. butzleri population held at $5^{\circ} \mathrm{C}$ over a period of 16 d. Campylobacter, a related genus, has been observed to demonstrate similar survival patterns. Korhonen and Martikainen (25) observed that $C$. jejuni survived significantly better at $4^{\circ} \mathrm{C}$ than at $25^{\circ} \mathrm{C}$. C. jejuni cells became undetectable after only $4 \mathrm{~d}$ at $25^{\circ} \mathrm{C}$ in $0.22 \mu \mathrm{m}$ filter-sterilized water. Thomas et al. (53) reported similar results for $C$. jejuni and C. coli, noting increased death rates as temperatures increased from $5^{\circ} \mathrm{C}$ to $37^{\circ} \mathrm{C}$ in sterile river water. Terzieva and McFeters (51) also noted a decline in viability of $C$. jejuni as temperatures increased from 6 to $16^{\circ} \mathrm{C}$.

Comparatively, the same pattern of decreased survival as the stress temperature increased was observed for E. coli (Figure 2). However, E. coli was notably more sensitive to groundwater stress than $A$. butzleri at all three exposure temperatures. In particular, no surviving $E$. coli cells were detected within one day when exposed to groundwater at $25^{\circ} \mathrm{C}$ (Figure 2). The lower D-values observed for E. coli at all three temperatures is a further indication of the increased sensitivity of $E$. coli as compared to A. butzleri to sterile groundwater stress (Table 7). These results compare favorably to 


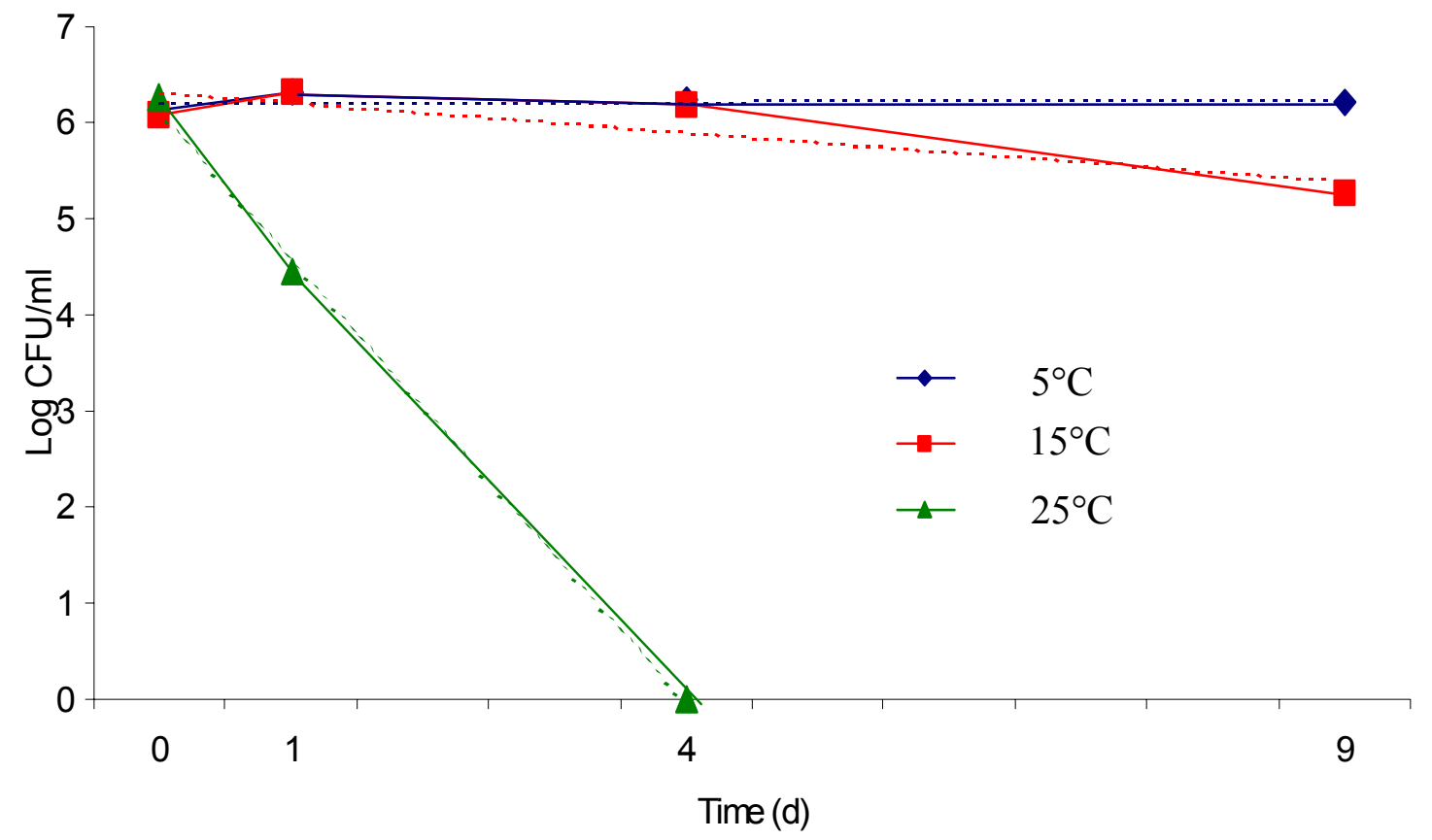

FIG. 1. Survival of Arcobacter butzleri after exposure to filter-sterilized groundwater at three different temperatures for $9 \mathrm{~d}$. All survivors detected on TSABL after $48 \mathrm{~h}$ of aerobic incubation at $30^{\circ} \mathrm{C}$. Each point represents the arithmetic mean of triplicate plate counts. Dotted lines represent regression lines for each set of data. 


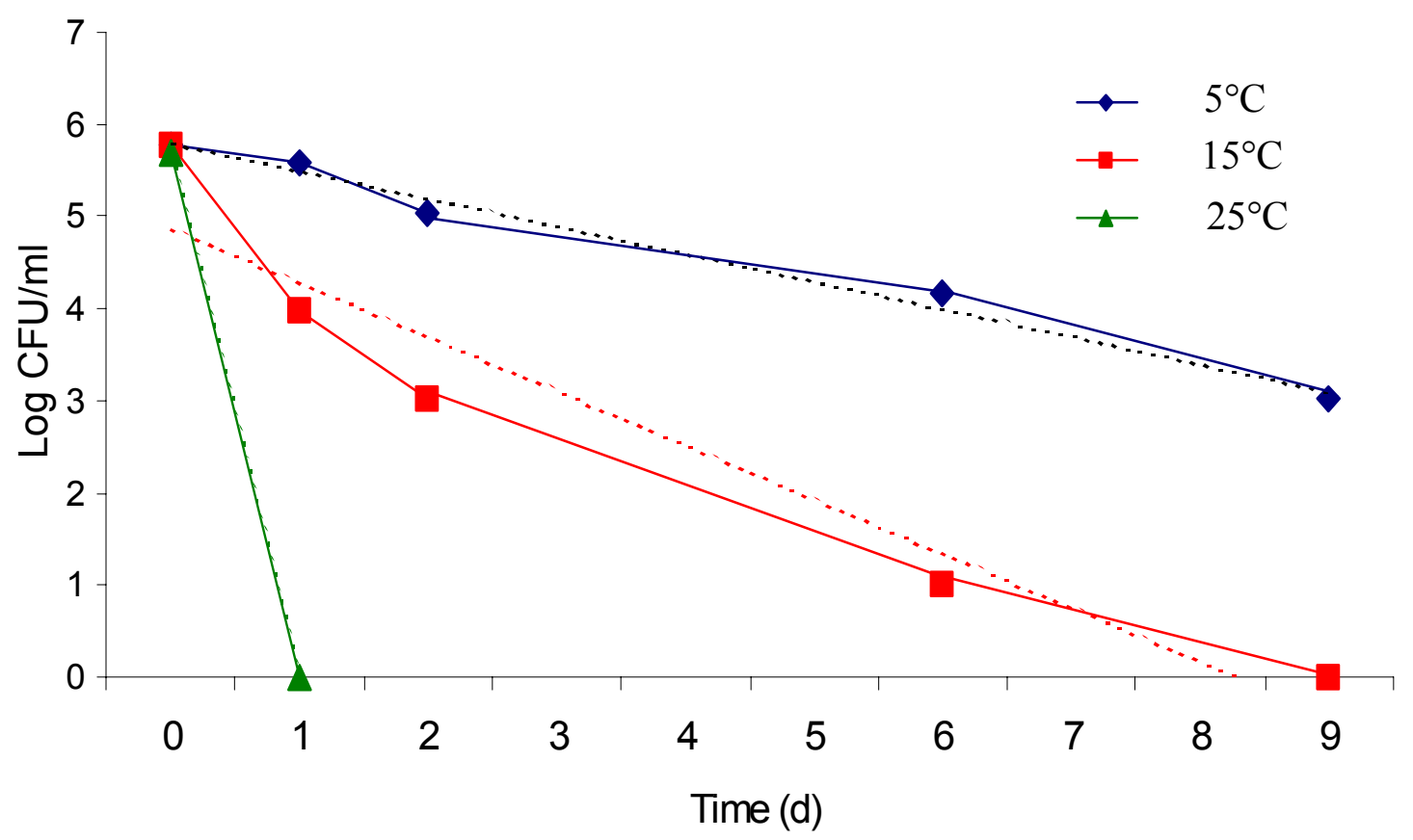

FIG. 2. Survival of Escherichia coli after exposure to filter-sterilized groundwater at three different temperatures for $9 \mathrm{~d}$. All survivors detected on NA after $24 \mathrm{~h}$ of aerobic incubation at $35^{\circ} \mathrm{C}$. Each point represents the arithmetic mean of triplicate plate counts. Dotted lines represent regression lines for each set of data. 
TABLE 7. Decimal reduction times for $E$. coli and $A$. butzleri after exposure to filter-sterilized groundwater at three different incubation temperatures

\begin{tabular}{ccc}
\hline & \multicolumn{2}{c}{ Decimal Reduction Time (days) } \\
\cline { 2 - 3 } Temperature $\left({ }^{\circ} \mathrm{C}\right)$ & E. coli & A. butzleri \\
\hline 5 & 3.3 & $-^{\mathrm{a}}$ \\
15 & 1.7 & 9.7 \\
25 & 0.2 & 0.6 \\
\hline
\end{tabular}

${ }^{\mathrm{a}} \mathrm{D}$-value not calculated since slightly more cells were detected after nine days than were initially placed in the microcosm. 
some existing data. Ducluzeau et al. (9) reported that washed E. coli cells inoculated at levels of $10^{3}$ and $10^{7} \mathrm{CFU} / \mathrm{ml}$ stored at $22^{\circ} \mathrm{C}$ did not survive more than 1 and $4 \mathrm{~d}$, respectively. Other studies, however, show drastically different results depending upon water source and the presence/absence of particulate matter $(12,24,26,41)$.

Persistence of groundwater-stressed $E$. coli and $A$. butzleri at $25^{\circ} \mathrm{C}$ in several different groundwater sources. It has long been recognized that nutrient concentration, water source, and even initial inoculum levels can play a significant role in the survival of microorganisms. Rice et al. (41) found that low nutrient-stressed E. coli held at $20^{\circ} \mathrm{C}$ could remain viable for up to $40 \mathrm{~d}$ when incubated in non-sterile groundwater. The addition of trace amounts of nutrients can, however, drastically increase survival. Ducluzeau et al. (9), found that when $10 \mathrm{mg}$ feces were introduced into $500 \mathrm{ml}$ mineral water, the survival of $10^{2} \mathrm{CFU} / \mathrm{ml}$ of $E$. coli was extended from 1 to $50 \mathrm{~d}$. Other studies have shown drastic changes in survival rates among different sources of water (24).

In this experiment survival of both $E$. coli and A. butzleri was monitored in several different groundwater sources. Four different water samples were obtained, and survival at $25^{\circ} \mathrm{C}$ was monitored over a 24 -h period. Again, E. coli proved more sensitive to all water sources (Figure 3). In every case, no cells were detected in any sample after only 24 h. E. coli survival was best in sample (S) water (recoverable cells after $18 \mathrm{~h}$ ), while the other three samples revealed no detectable cells after $2 \mathrm{~h}(\mathrm{P} 2), 12 \mathrm{~h}(\mathrm{P} 1)$, and 18 h (VP), respectfully. A. butzleri seemed to have much different response to the water sources (Figure 4). A. butzleri died after only $4 \mathrm{~h}$ in water sample $\mathrm{P} 2$, however significant cell loss was not seen over the $24 \mathrm{~h}$ period for the other three water sources. Table 8 represents the corresponding D-value for each bacterium, in each source water. 


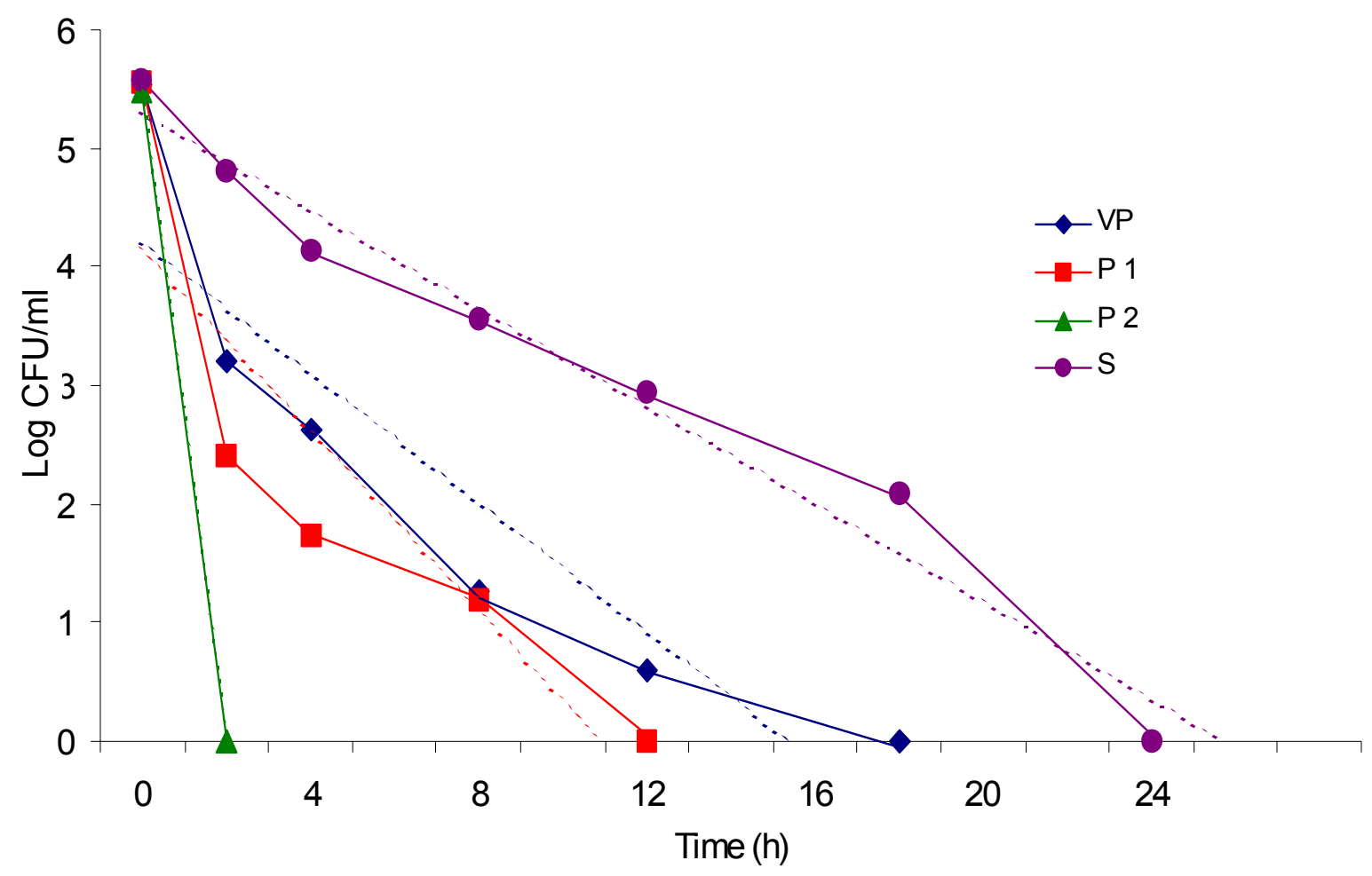

FIG. 3. Survival of Escherichia coli in several filter-sterilized groundwater sources over a $24-\mathrm{h}$ period at $25^{\circ} \mathrm{C}$. All survivors detected on NA after $24 \mathrm{~h}$ of aerobic incubation at $35^{\circ} \mathrm{C}$. Each data point represents the arithmetic mean of triplicate plate counts. Dotted lines represent regression lines for each set of data. 


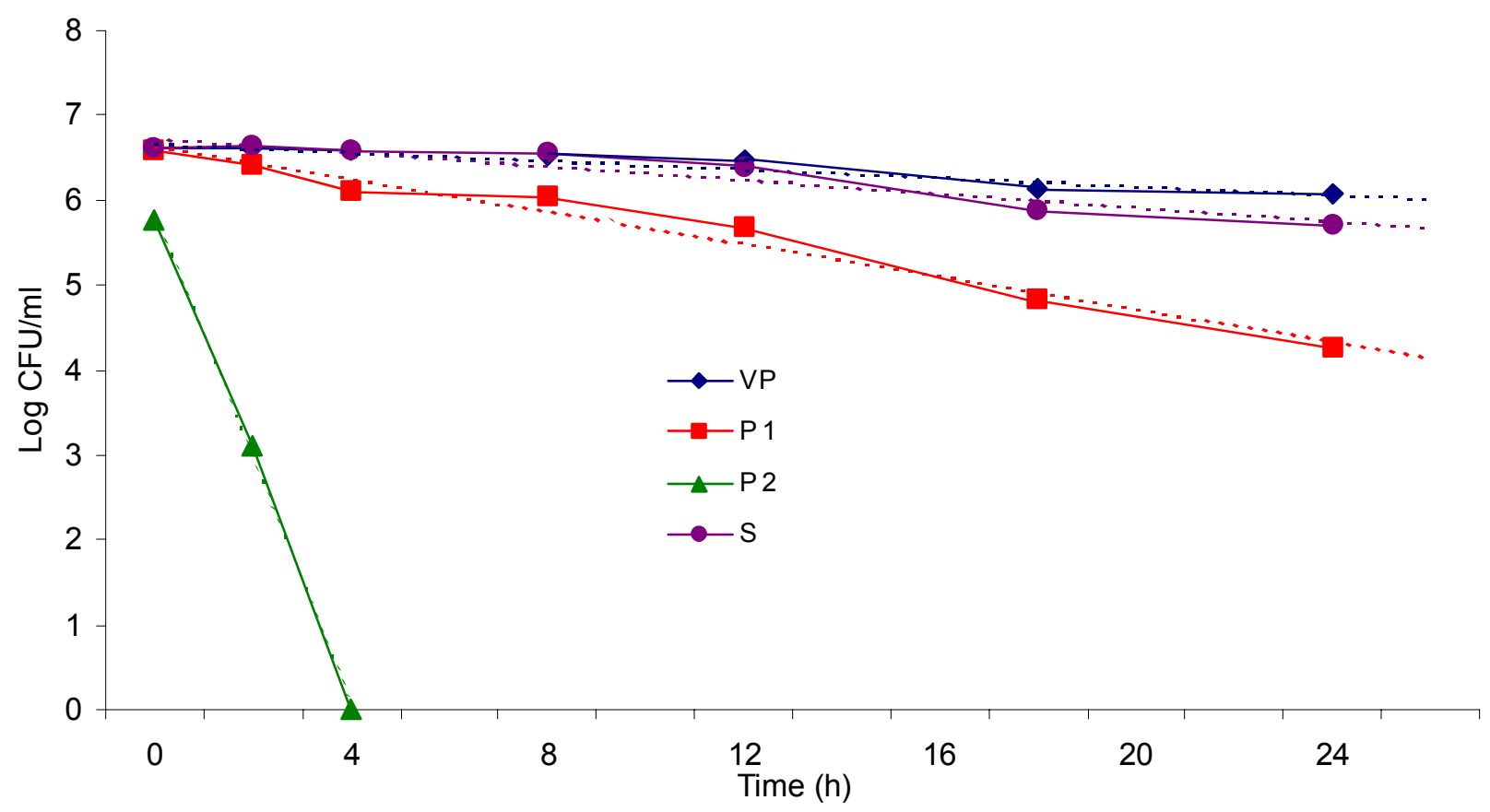

FIG. 4. Survival of Arcobacter butzleri in several filter-sterilized groundwater sources over a 24 -h period at $25^{\circ} \mathrm{C}$. All survivors detected on TSABL after $2 \mathrm{~d}$ of aerobic incubation at $30^{\circ} \mathrm{C}$. Each data point represents the arithmetic mean of triplicate plate counts. Dotted lines represent regression lines for each set of data. 
TABLE 8. Decimal reduction times for E. coli and A. butzleri after exposure to filter-sterilized groundwater sources at $25^{\circ} \mathrm{C}$

\begin{tabular}{ccc}
\hline & \multicolumn{2}{c}{ Decimal Reduction Time (hours) } \\
\cline { 2 - 3 } Water Source & E. coli & A. butzleri \\
\hline VP & 1.1 & 16.4 \\
P1 & 1.3 & 5.1 \\
P2 & 0.2 & 0.4 \\
S & 2.4 & 12.6 \\
\hline
\end{tabular}


These data strengthen the notion that $E$. coli is more sensitive to low-nutrient groundwater stress than is A. butzleri.

\section{Recovery of groundwater-stressed $\mathrm{A}$.butzleri cells in well water at $15^{\circ} \mathrm{C}$ and}

$25^{\circ} \mathrm{C}$ on several selective media. Low nutrient-stress and temperature fluctuations within different environments can have a profound effect on cells. Cells have been known to shrink in size, alter metabolism, or even enter a viable but non-culturable (VBNC) state (45). The use of selective, antimicrobial containing media relies upon the fact that microorganisms, once stressed, retain their resistance to certain concentrations of these antimicrobial compounds. Arcobacters exist in the environment concurrently with countless species of bacteria. To selectively isolate arcobacters, several existing commercial media incorporate antibiotics to prevent growth of competitive flora. Although a particular bacterium may be resistant to a certain concentration of a particular antibiotic while growing under optimum conditions, it can act quite differently after being stressed.

After $9 \mathrm{~d}$ of low-nutrient stress at $15^{\circ} \mathrm{C}$, there was a significant loss of cell recovery using media amended with antimicrobial compounds $(\mathrm{p}<0.05)$ (Table 9). After $4 \mathrm{~d}$, no significant loss could be detected. Although statistically significant, only 17 to 32 $\%$ of the survivors were sublethally injured after $9 \mathrm{~d}$ and only 16 to 32 percent injured after $4 \mathrm{~d}$ (Figure 5). These recovery rates are acceptable considering that using a Columbia blood agar based medium, 77 to $83 \%$ of the initial population could still be recovered after $9 \mathrm{~d}$.

Although little difference was seen in recovery efficiency of all selective media at $15^{\circ} \mathrm{C}$, D-values previously reported for $A$. butzleri indicate that $15^{\circ} \mathrm{C}$ groundwater 
TABLE 9. Sensitivity of selective media for detection of $A$. butzleri following exposure to filter-sterilized groundwater at $15^{\circ} \mathrm{C}$ for 4 and $9 \mathrm{~d}$

\begin{tabular}{lccccc}
\hline \multirow{2}{*}{ Medium } & \multicolumn{2}{c}{4 day $^{\text {Recovered cells }}{ }^{\mathrm{a}}$} & \% Injury $^{\mathrm{b}}$ & & \multicolumn{2}{c}{9 day } \\
\cline { 2 - 3 } \cline { 5 - 6 } & Recovered cells $^{\mathrm{a}}$ & \% Injury $^{\mathrm{b}}$ \\
\hline TSABL & $6.19 \mathrm{a}$ & - & $5.27 \mathrm{a}$ & - \\
COLCCDA & $6.11 \mathrm{a}$ & 16.8 & & $5.15 \mathrm{~b}$ & 24.1 \\
COLCAT & $6.11 \mathrm{a}$ & 17.1 & & $5.19 \mathrm{bc}$ & 16.8 \\
ABMCONT & $6.11 \mathrm{a}$ & 16.4 & & $5.16 \mathrm{bc}$ & 22.4 \\
ABMCCDA & $6.10 \mathrm{a}$ & 18.7 & & $5.14 \mathrm{bc}$ & 25.9 \\
ABMCAT & $6.02 \mathrm{~b}$ & 32.4 & & $5.10 \mathrm{c}$ & 32.4 \\
\hline
\end{tabular}

${ }^{a} \log \mathrm{CFU} / \mathrm{ml}$ (arithmetic means of triplicate plate counts) following aerobic incubation at $30^{\circ} \mathrm{C}$ for $2 \mathrm{~d}$. Values with different letters indicate significant differences in recovery at $\mathrm{p}<0.05$.

${ }^{\mathrm{b}}$ Percent injury calculated from raw CFU/ml counts and not from $\mathrm{Log} \mathrm{CFU} / \mathrm{ml}$ data. 


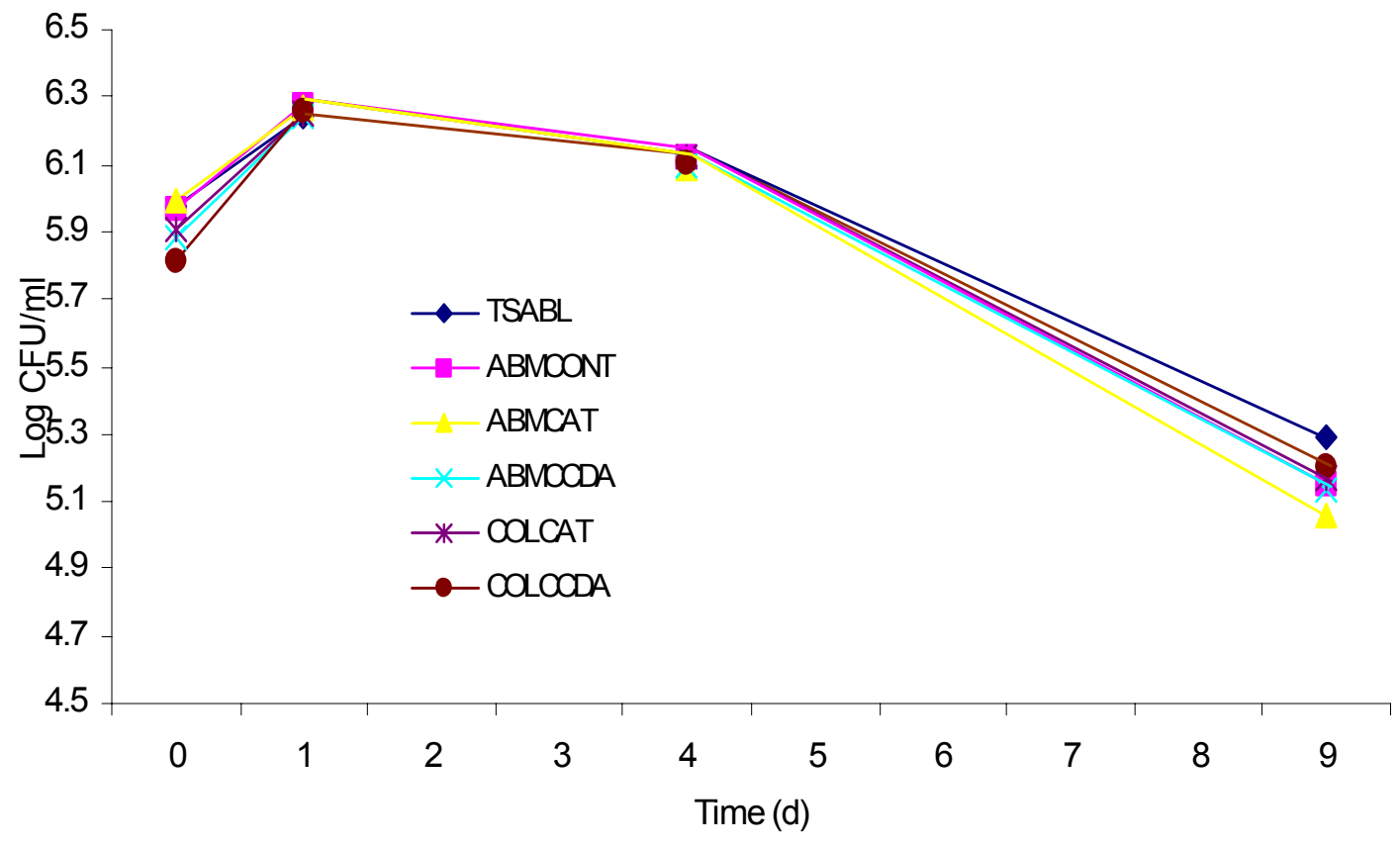

FIG. 5. Recovery of Arcobacter butzleri on several selective media after exposure to filter-sterilized groundwater at $15^{\circ} \mathrm{C}$ over a period of 9 days. All plates incubated aerobically at $30^{\circ} \mathrm{C}$ for $48 \mathrm{~h}$. Each point represents the arithmetic mean of triplicate plate counts from duplicate flasks $(n=6)$. 
exposure may not correspond to a high degree of stress. Recovery of A. butzleri was next monitored at $25^{\circ} \mathrm{C}$ (Figure 6). At this temperature, much more stressful to A. butzleri, differences were observed between recovery media. At the 24-h sampling point statistical differences were evident $(\mathrm{p}<0.05)$ (Table 10). Regardless of medium used, however, 80 to 89 percent of the initial population could be recovered (Table 10). After $48 \mathrm{~h}$, however, larger differences $(\mathrm{p}<0.05)$ in recovery were observed. Columbia blood agar based media were able to recover, in some cases, greater than 30 percent more cells than ABM based media could ( 76 to $78 \%$ as compared to 49 to $51 \%$ ). These data indicate clear and distinct differences in recovery between ABM-based and COL-based media. At both $15^{\circ} \mathrm{C}$ and $25^{\circ} \mathrm{C}$, TSABL was the most effective medium used, consistently yielding the highest counts. Both Columbia-based media (COLCCDA and COLCAT) were the next best for recovery, closely rivaling the results of TSABL. Finally, in all cases, ABM based media were inferior, in some cases recovering 30 percent less bacteria than other media at equivalent times and temperatures. Antibiotic supplements seemed to have minimal effect on recovery efficiency. There appeared to be little or no difference in recovery rates between CAT supplement and CCDA supplement. This is not at all surprising since both media are designed to recover Arcobacter spp., whereas CCDA supplement is specific to A. butzleri which was used for these studies. These results may prove promising. Columbia blood agar base combined with blood and selective antimicrobials was able to recovery between 76 and $89 \%$ of stressed cells regardless of sampling time or water temperature when compared to that of TSABL which lacks the ability to deter any background flora. For the remaining studies, COLCCDA was utilized in attempts to recover arcobacters from environmental sources. 


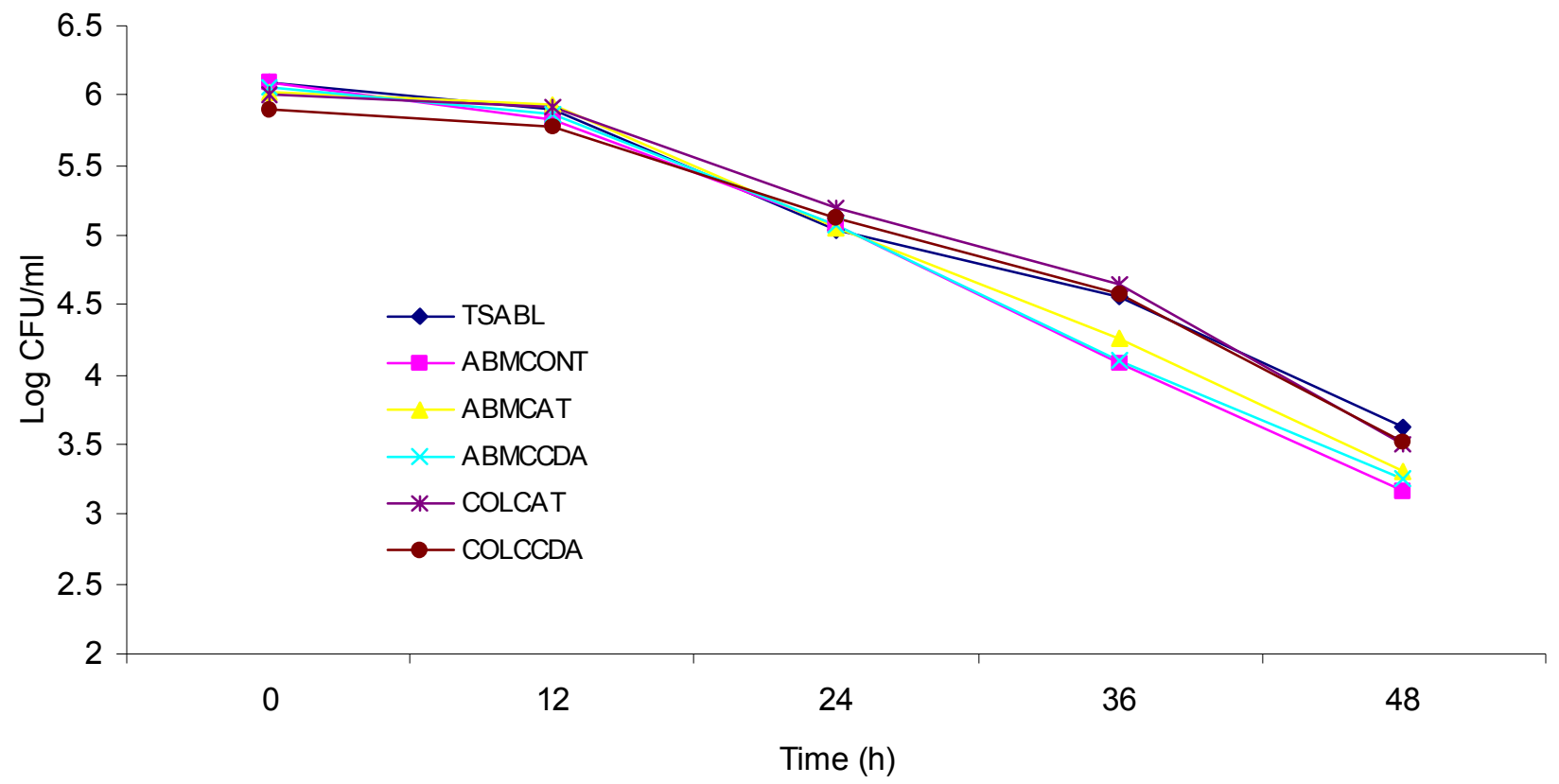

FIG. 6. Recovery of Arcobacter butzleri on several selective media after exposure to filter-sterilized groundwater at $25^{\circ} \mathrm{C}$ over a period of $48 \mathrm{~h}$. All plates incubated aerobically at $30^{\circ} \mathrm{C}$ for $48 \mathrm{~h}$. Each point represents the arithmetic mean of triplicate plate counts from duplicate flasks $(n=6)$. 
TABLE 10. Sensitivity of selective media for detection of $A$. butzleri following exposure to filter-sterilized groundwater at $25^{\circ} \mathrm{C}$ for 24 and $48 \mathrm{~h}$

\begin{tabular}{lccccc}
\hline & \multicolumn{2}{c}{24 hour } & & \multicolumn{2}{c}{48 hour } \\
\cline { 2 - 3 } \cline { 5 - 6 } Medium & Recovered Cells $^{\mathrm{a}}$ & \% Injury & & Recovered Cells $^{\mathrm{a}}$ & \% Injury \\
\hline TSABL & $5.16 \mathrm{a}$ & - & & $3.63 \mathrm{a}$ & - \\
COLCCDA & $5.11 \mathrm{~b}$ & 10.9 & & $3.51 \mathrm{~b}$ & 24.1 \\
COLCAT & $5.19 \mathrm{a}$ & -7.1 & & $3.52 \mathrm{~b}$ & 22.4 \\
ABMCAT & $5.06 \mathrm{~b}$ & 20.4 & & $3.34 \mathrm{c}$ & 48.7 \\
ABMCCDA & $5.06 \mathrm{~b}$ & 20.1 & & $3.32 \mathrm{c}$ & 51.0 \\
ABMCONT & $5.06 \mathrm{~b}$ & 19.7 & & $3.16 \mathrm{~d}$ & 66.1 \\
\hline
\end{tabular}

${ }^{a} \mathrm{Log} \mathrm{CFU} / \mathrm{ml}$ (arithmetic means of triplicate plate counts) following aerobic incubation at $30^{\circ} \mathrm{C}$ for $2 \mathrm{~d}$. Values with different letters indicate significant differences in recovery at $\mathrm{p}<0.05$.

${ }^{\mathrm{b}}$ Percent injury calculated from raw $\mathrm{CFU} / \mathrm{ml}$ counts and not from $\mathrm{Log} \mathrm{CFU} / \mathrm{ml}$ data. 


\section{Use of COLCCDA medium for direct isolation of $\boldsymbol{A}$. butzleri from raw}

sewage. Due to the lack of an effective selective isolation medium, Arcobacter spp. have yet to be quantified in any environmental source. Methods exist for detection but only presence/absence can be determined $(4,14,15,19,22,31,42,49)$. However, for proper control of the spread and growth of this bacterium, baseline population levels need to be established in various environments.

Spread plates (COLCCDA agar) inoculated with raw sewage were allowed to incubate for 2 days before plates were observed for countable colonies. Observation revealed complete overgrowth of plates by indigenous sewage flora. The concentrations and types of antibiotics incorporated into the selective medium were not inhibitory enough to other microorganisms present in sewage. Too much background flora remained to effectively isolate and differentiate arcobacter-like colonies (colonies which displayed typical colony morphology on TSABL, i.e. round white, off-white, or grayish colonies 2 to $4 \mathrm{~mm}$ in diameter after 2 days of incubation, and displayed typical gramnegative helical, curved, or S-shaped rods) from others. Table 11 shows the colony counts under several different selective incubation conditions. By incubating COLCCDA plates under microaerophilic conditions at $15^{\circ} \mathrm{C}$, background flora could be reduced approximately 10 -fold. This reduction, however, is not nearly enough to effectively isolate $A$. butzleri from any environment encountered thus far.

\section{Isolation of $A$. butzleri from serially diluted and spiked raw sewage samples.} Although it has been documented that $A$. butzleri is present in raw sewage $(47,48)$, there was no definitive way to know if the present sample, in fact, was arcobacter positive. A sewage sample was next obtained, serially diluted to reduce background flora, and 
TABLE 11. Plate counts of raw sewage under various incubation conditions

\begin{tabular}{lclcc}
\hline Medium & Temperature & Incubation & Time & Recovered cells $^{\mathrm{a}}$ \\
\hline $\mathrm{R}^{\mathrm{b}} \mathrm{A}^{\mathrm{b}}$ & $28^{\circ} \mathrm{C}$ & Aerobic & $5 \mathrm{~d}$ & 6.95 \\
$\mathrm{COLCCDA}$ & $15^{\circ} \mathrm{C}$ & Aerobic & $2 \mathrm{~d}$ & 6.80 \\
$\mathrm{COLCCDA}$ & $30^{\circ} \mathrm{C}$ & Microaerophilic & $2 \mathrm{~d}$ & 6.17 \\
$\mathrm{COLCCDA}$ & $15^{\circ} \mathrm{C}$ & Microaerophilic & $2 \mathrm{~d}$ & 5.71 \\
\hline
\end{tabular}

${ }^{a} \mathrm{Log} \mathrm{CFU} / \mathrm{ml}$ (arithmetic mean of triplicate plate counts).

${ }^{\mathrm{b}} \mathrm{HPC}$ performed on $\mathrm{R} 2 \mathrm{~A}$ incubated aerobically at $28^{\circ} \mathrm{C}$ for $5 \mathrm{~d}$ 
spiked, in order to see if typical arcobacter colony morphologies would be distinguishable from those of normal indigenous sewage flora, at different background population levels. After spread plating (on COLCCDA agar) and $15^{\circ} \mathrm{C}$ microaerophilic incubation for $4 \mathrm{~d}$, plates were observed for typical arcobacter colony morphology. It became clear that typical arcobacter-like colonies were only observable when sewage populations approximated that of arcobacter. No matter how high the arcobacter population, if sewage flora was present in levels greater than 10 times of that of arcobacter, no colony distinction could be made.

Isolation of competing flora and partial characterization of isolates. In an attempt to identify prominent competitors on the selective agar, isolates of the most abundant organisms were picked and characterized. Such information should aid in the design of a new or modified selective isolation medium for arcobacters. Each isolate was characterized according to some basic staining and physiological tests (Table 12). Isolates showed very little metabolic diversity. Simmons citrate utilization, and in one case, casein digestion and glucose fermentation, were the only differing biochemical tests. Gram reaction and morphology did, however, vary between isolates.

\section{Survey of chicken fecal matter and water from feeders: Spread plating and}

multiplex PCR. Previous attempts to quantify $A$. butzleri in a sewage environment proved ineffective. Only a 10 -fold reduction in indigenous sewage flora was observed through selective incubation. This poor reduction may be attributed to the types and quantities of antibiotics incorporated into COLCCDA agar. Originally the CCDA supplement was designed for use in isolation of Campylobacter spp. from poultry samples. By changing the concentrations of the antibiotics, the supplement was altered to 
TABLE 12. Summary of sewage isolate characteristics

\begin{tabular}{|c|c|c|c|c|c|c|c|c|c|}
\hline Isolate group & 1 & 2 & 3 & 4 & 5 & 6 & 7 & 8 & 9 \\
\hline Gram reaction & - & - & - & + & - & + & - & + & - \\
\hline Morphology & Coccus & Coccus & Diplococcus & Coccus & Coccus & Bacillus & Diplococcus & Bacillus & Diplococcus \\
\hline $24 \mathrm{~h}$ growth in NA & + & + & + & + & + & + & + & + & + \\
\hline $\begin{array}{l}\text { Oxygen } \\
\text { requirements }\end{array}$ & $\mathrm{A} / \mathrm{M}^{\mathrm{a}}$ & $\mathrm{A} / \mathrm{M}$ & $\mathrm{A} / \mathrm{M}$ & $\mathrm{A} / \mathrm{M}$ & $\mathrm{A} / \mathrm{M}$ & $\mathrm{A} / \mathrm{M}$ & $\mathrm{A} / \mathrm{M}$ & $\mathrm{A} / \mathrm{M}$ & $\mathrm{A} / \mathrm{M}$ \\
\hline Mannitol $^{\mathrm{b}}$ & - & - & - & - & - & - & - & - & - \\
\hline Glucose $^{b}$ & - & - & - & - & - & - & - & - & $\begin{array}{l}+ \text { acid } \\
- \text { Gas }\end{array}$ \\
\hline Lactose $^{b}$ & - & - & - & - & - & - & - & - & - \\
\hline $\begin{array}{l}\text { Phenylalanine } \\
\text { deaminase }\end{array}$ & + & + & + & + & + & + & + & + & + \\
\hline Indole & - & - & - & - & - & - & - & - & - \\
\hline Methyl red & - & - & - & - & - & - & - & - & - \\
\hline Voges Proskauer & - & - & - & - & - & - & - & - & - \\
\hline Simmons citrate & - & - & + & - & - & - & + & + & + \\
\hline Urease & - & - & - & - & - & - & - & - & - \\
\hline $\begin{array}{l}\text { Motility (SIM } \\
\text { medium) }\end{array}$ & - & - & - & - & - & - & - & - & - \\
\hline $\mathrm{H}_{2} \mathrm{~S}$ (SIM) & - & - & - & - & - & - & - & - & - \\
\hline Starch hydrolysis & - & - & - & - & - & - & - & - & - \\
\hline Catalase & + & + & + & + & + & + & + & + & + \\
\hline Oxidase & - & - & - & - & - & - & - & - & - \\
\hline Caesin hydrolysis & - & - & - & - & - & - & - & + & - \\
\hline
\end{tabular}

${ }^{a}$ Aerobe/microaerophile

${ }^{\mathrm{b}}$ Fermentation reactions 
allow selective isolation of $A$. butzleri. This specific combination, therefore, may be more selective in inhibiting flora normally associated with poultry.

Enrichment cultures of each sample were prepared to ensure that plate detection of $A$. butzleri corresponded to molecular detection. Whereas individual colonies would have to be present on plates for detection, multiplex PCR can detect $A$. butzleri without selective isolation from the environment.

Results of multiplex PCR detection show two of the samples gave positive results (Figure 7). Lanes 7, 10, and 12 all show a $686 \mathrm{bp}$ and $1223 \mathrm{bp}$ amplification product denoting A. butzleri (lane12 represents a positive control). Water sample 1 from a turkey waterer proved positive (lane 7) as did spiked water sample three (lane 10). Both of these samples had relatively low levels of indigenous flora along with a general lack of particulate matter in the broths. These factors may have contributed to the effective detection by Multiplex PCR. Curiously, fecal sample 4 spiked with $10^{4} \mathrm{CFU} / \mathrm{ml}$ of $A$. butzleri did not give positive results. Two factors may be attributed to this. Again, both water samples had relatively low levels of particulate matter as compared to the fecal samples. Although the broths were not vortexed after enrichment, liquid taken from fecal samples for processing was very cloudy with much suspended particulate matter. There may have been enough particulate matter present to inhibit detection. A centrifuging/cell washing procedure similar to the one described by Houf et al. (19) may be necessary in order to remove this particulate matter and increase detection sensitivity. Second, comparing samples, fecal sample 4 had a much higher background flora population (7.91 Log CFU/ml) than did water sample 1 (2.15 Log CFU/ml) or 3 (3.68 Log CFU/ml) while fecal sample 4 and water sample 3 incorporated the same spike level of $10^{4} \mathrm{CFU} / \mathrm{ml}$ 


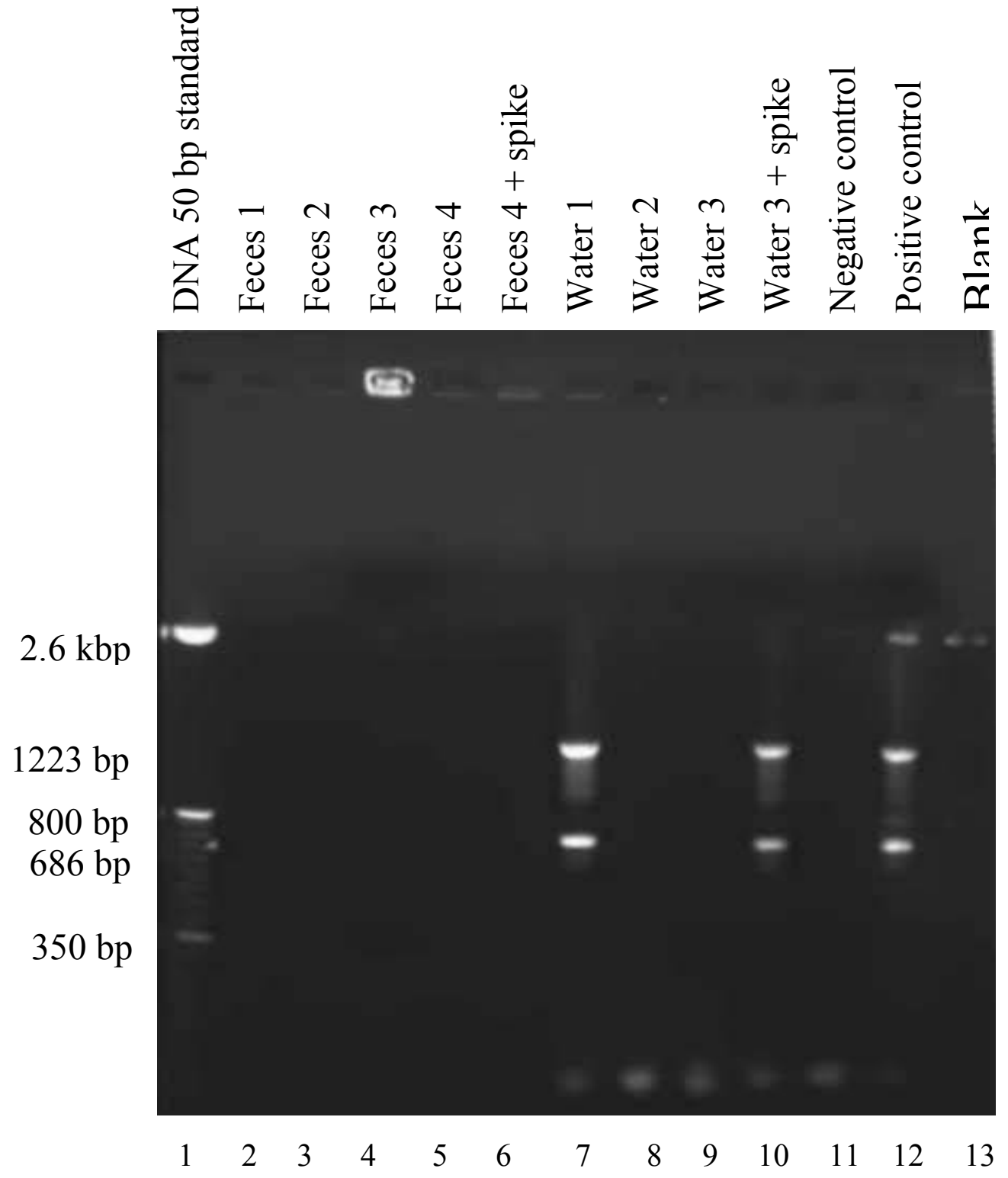

FIG. 7. Multiplex PCR results for chicken and fecal samples. Lane 1 represents a $50 \mathrm{bp}$ standard, lanes 2-5 represent fecal samples 1-4, lane 6 represents fecal sample 4 spiked with $10^{4}$ CFU/g A. butzleri, Lanes 7-9 represent water samples 1-3, lane 10 represents water sample 3 spiked with $10^{4} \mathrm{CFU} / \mathrm{ml}$ A. butzleri, lane 11 represents a sterile uninoculated enrichment broth, and lane 12 represents a $48 \mathrm{~h}$ culture of $A$. butzleri grown in enrichment broth. 
A. butzleri. The higher levels of indigenous flora present in the spiked fecal sample may have masked the arcobacter population, resulting in a lack of detection.

Selectively enriched plates were next examined. It was anticipated that selective enrichment would inhibit background flora allowing the isolation of A. butzleri colonies. Differentiation between arcobacter and indigenous flora colonies, however, was nearly impossible. Again, background flora levels remained high even after incubation under the most selective conditions. Background flora levels were only reduced by up to $2 \log$ units (Table 13). In particular, spiked fecal sample F4 showed poor results. Due to the high numbers of indigenous sewage microorganisms present, (6.76 Log CFU/g under selective incubation), the $10^{4} \mathrm{CFU} / \mathrm{g}$ spike was completely masked and no differentiation could be made. Only in water samples W1 \& W3 was there a clear distinction between colonies. After a 100-fold dilution of spiked sample W3, only arcobacter colonies remained to be counted. This success was attributed to the low HPC $\left(4.8 \times 10^{3}\right)$ of the water sample along with a high spike population $\left(\sim 5.0 \times 10^{4}\right)$ of $A$. butzleri. Water sample W1, though not spiked, however, along with being PCR positive, did demonstrate the presence of arcobacter-like colonies.

Though plate detection of spiked samples proved somewhat effective it was not known if the use of enrichment techniques could suppress background flora growth while allowing the proliferation of arcobacters. Previous results indicate that a relationship may exist between presence of particulate matter in the sample, ratio of A. butzleri to normal flora, and detection by multiplex PCR.

\section{Molecular detection and spread plate isolation of $A$. butzleri from raw}

sewage. Currently, molecular methods can be employed to test for the presence/absence 
TABLE 13. Selective plate-count colony reduction for fecal and water samples from poultry

\begin{tabular}{llccc}
\hline Sample & Medium $^{\mathrm{a}}$ & Count $^{\mathrm{b}}$ & Reduction $^{\mathrm{b}}$ & Arco-like colonies present $^{\text {Fr }}$ \\
\hline F1 & HPC & 7.26 & - & ND $^{\mathrm{e}}$ \\
F1 & COLCCDA & 5.28 & 1.98 & - \\
F2 & HPC & 7.98 & - & ND \\
F2 & COLCCDA & 6.54 & 1.44 & - \\
F3 & HPC & 7.73 & - & ND \\
F3 & COLCCDA & 6.32 & 1.41 & - \\
F4 & HPC & 7.91 & - & ND \\
F4 & COLCCDA & 6.76 & 1.15 & - \\
F4S & COLCCDA & 6.48 & 1.43 & - \\
W1 & HPC & 2.15 & - & ND \\
W1 & COLCCDA & 1.72 & 0.43 & + \\
W2 & HPC & 3.56 & - & ND \\
W2 & COLCCDA & 2.86 & 0.70 & - \\
W3 & HPC & 3.68 & - & ND \\
W3 & COLCCDA & 2.71 & 0.97 & - \\
W3S & COLCCDA & 4.52 & $(+)^{\mathrm{d}}$ & + \\
\hline
\end{tabular}

${ }^{\mathrm{a}} \mathrm{HPC}$ plated on R2A incubated aerobically at $28^{\circ} \mathrm{C}$ for $5 \mathrm{~d}$. COLCCDA plates incubated microaerophilically at $15^{\circ} \mathrm{C}$ for $4 \mathrm{~d}$.

${ }^{\mathrm{b}}$ Counts reported are $\mathrm{Log} \mathrm{CFU} / \mathrm{ml}$ or $\mathrm{g}$.

${ }^{\mathrm{c}} \mathrm{S}$ indicates sample was spiked with approximately $5.0 \times 10^{4} \mathrm{CFU} / \mathrm{ml}$ or $\mathrm{g}$ A. butzleri.

${ }^{\mathrm{d}}$ Reduction positive since spike was larger than HPC of water sample.

${ }^{\mathrm{e}} \mathrm{ND}=$ not determined. 
of $A$. butzleri in an environmental sample. Little is known, however, how sensitive these methods are and what types and amounts of flora indigenous to the sample may be inhibitory. Due to the high levels of particulate matter present in fecal samples, detection of $A$. butzleri from a raw sewage sample was attempted. Initial sewage plate counts were preformed to establish baseline populations and reduction by selective plating and incubation (Table14). Approximately a 10-fold reduction was again seen in sewage flora on selective COLCCDA.

Figure 8 shows results from multiplex PCR detection. Lanes 8 and 10-17 denote positive samples. Both a 1223 and 686 bp product was observable in all positive samples suggesting the presence of $A$. butzleri (lanes 8 and 10-14 contained faint $686 \mathrm{bp}$ fragments but clear visibility was lost upon reproduction of photograph). Lanes 5-10 represent spiked sewage enrichments before $4 \mathrm{~d} 15^{\circ} \mathrm{C}$ microaerophilic incubation. Lanes 11-16 represent enrichments after incubation. Attention specifically should be paid to lane 8 , as this represented the lower detection limit. It shows that given no enrichment and with sewage flora present in full strength, A. butzleri must be present in minimum concentrations of approximately $10^{4} \mathrm{CFU} / \mathrm{ml}$ for multiplex PCR detection. Lane 3 , the sewage sample spiked with $A$. butzleri did not give positive results. Again, this may simply represent a detection limit error. With a spike of only $10^{4} \mathrm{CFU} / \mathrm{ml}$ A. butzleri, high levels of sewage flora may have masked arcobacter cell detection. Also, the spike was at the detection limit and could prove to be unreliable.

Only one other report of a threshold level for multiplex PCR detection of arcobacter cells has been reported. Houf et al. (19) reported that when arcobacter broth with CAT selective supplement was used to enrich spiked samples of poultry skin 
TABLE 14. Colony counts for raw sewage samples incubated on nonselective R2A and selective COLCCDA

\begin{tabular}{lcc}
\hline Medium & Spiked & Colonies present $^{\mathrm{d}}$ \\
\hline $\mathrm{R}^{\mathrm{a}} \mathrm{A}^{\mathrm{a}}$ & No & 6.88 \\
COLCCDA $^{\mathrm{b}}$ & No & 5.72 \\
COLCCDA $^{\mathrm{b}}$ & Yes $^{\mathrm{c}}$ & 5.70 \\
\hline
\end{tabular}

${ }^{a} \mathrm{HPC}$ preformed on R2A incubated aerobically at $28^{\circ} \mathrm{C}$ for $5 \mathrm{~d}$.

${ }^{\mathrm{b}}$ Incubated at $15^{\circ} \mathrm{C}$ microaerophilically for $4 \mathrm{~d}$.

${ }^{\mathrm{c}}$ Spiked at approximately $5.0 \times 10^{4} \mathrm{CFU} / \mathrm{ml}$.

${ }^{\mathrm{d}} \mathrm{Log} \mathrm{CFU} / \mathrm{ml}$. 


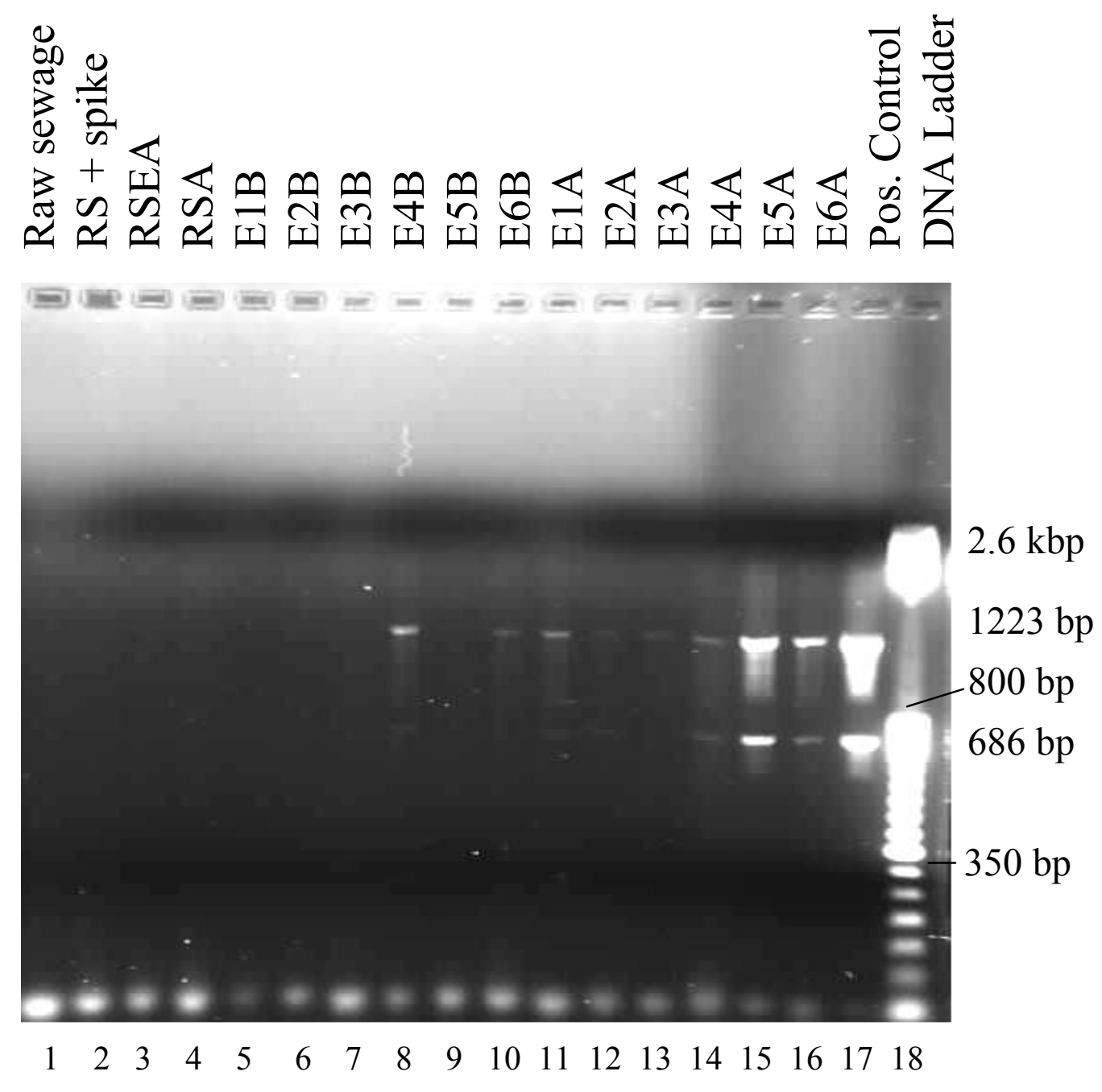

FIG. 8. Multiplex PCR results for sewage enrichment broths. Lanes 1 and 4 represent a raw sewage sample, lane 2 represents a duplicate sample spiked with $10^{4} \mathrm{CFU} / \mathrm{ml}$ A. butzleri, and lane 3 represents raw sewage in enrichment broth. In lanes 5- 16, E represents enrichment broth and the number represents " $\mathrm{x}$ " in a $10^{\mathrm{x}} \mathrm{CFU} / \mathrm{ml}$ Spike of A. butzleri. Lane 17 represents a $48 \mathrm{~h}$ culture of $A$. butzleri grown in enrichment broth, and lane 18 represents a $50 \mathrm{bp}$ standard. In each case the letter $\mathrm{B}$ represents before, and $\mathrm{A}$, after microaerophilic incubation at $15^{\circ} \mathrm{C}$ for $4 \mathrm{~d}$. 
or meat, minimum detection levels needed were at about $10^{3} \mathrm{CFU} / \mathrm{g}$ A. butzleri per sample. The use of sewage in this experiment may be the reason for the higher detection limit. Number and type of bacteria present may be different and, thus skew the detection limit.

Next, spiked enrichment plates were observed for countable arcobacter-like colonies vs. total colonies. Table 15 shows the relationship between PCR lane, total arcobacter-like colonies, total colonies, and percent arcobacter-like colonies. A direct correlation between initial spike level and percent of total arcobacter-like colonies recovered was observed. All spike levels eventually reached levels between $10^{7}$ and $10^{8}$ $\mathrm{CFU} / \mathrm{ml}$, indicating that there was an observable selective advantage for A. butzleri in the enrichments. Enrichment conditions may slow competitor growth enough to allow arcobacter proliferation. There was also an advantage to having higher initial populations of arcobacter present in a sample. Enrichments, which were spiked at higher levels before incubation, demonstrated a larger $\%$ arcobacter-like colony count upon plating. This may represent the ability of Arcobacter spp. to out-compete other microorganisms under the given set of incubation conditions.

Overall, A. butzleri responded very well to enrichment. As little as $10^{1} \mathrm{CFU} / \mathrm{ml}$ A. butzleri inoculated into a fecal sample could be detected by multiplex PCR after enrichment. Without enrichment, however results vary. In some cases the population of A. butzleri cells in a sample must exceed $10^{4} \mathrm{CFU} / \mathrm{ml}$ or $\mathrm{g}$ to be detected. A filtration/centrifugation/nucleic acid purification process may be necessary to remove particulate matter and increase detection efficiency. 
TABLE 15. Percent $A$. butzleri-like colonies recovered after spread plating enrichment broths spiked with different levels of $A$. butzleri

\begin{tabular}{cccc}
\hline Enrichment sample & CFU/ml Arco-like colonies & Total colonies $^{\mathrm{a}}$ & \% Arco-like colonies $^{\mathrm{a}}$ \\
\hline 11 & $2.5 \times 10^{7}$ & $8.6 \times 10^{7}$ & 28.49 \\
12 & $5.6 \times 10^{7}$ & $1.4 \times 10^{8}$ & 40.88 \\
13 & $7.2 \times 10^{7}$ & $1.6 \times 10^{8}$ & 45.54 \\
14 & $1.1 \times 10^{8}$ & $1.7 \times 10^{8}$ & 66.18 \\
15 & $1.5 \times 10^{8}$ & $2.0 \times 10^{8}$ & 72.37 \\
16 & $2.0 \times 10^{8}$ & $2.7 \times 10^{8}$ & 76.03 \\
\hline
\end{tabular}

${ }^{a}$ Counts are arithmetic means of two replicate plate counts. 
Plate detection, however, was found to be poor. In no circumstance could background flora populations be reduced by more than $2 \log$ units. This reduction proved insufficient for reliable and accurate detection of arcobacters from domestic sewage, poultry fecal matter, and poultry waterers. 


\section{SUMMARY}

Optimum recovery of Arcobacter spp. from clinical and environmental sources has been previously been debated. Some studies report arcobacters as aerotolerant organisms with optimum growth occurring under microaerophilic conditions. Other studies suggest that with the addition of oxygen scavenging compounds like blood and charcoal to nutrient-rich growth media, the need for microaerophilic incubation can be reduced, allowing Arcobacter spp. to tolerate aerobic incubation. The current study suggests that, in fact, the addition of blood to a nutrient-rich growth medium such as TSA can enhance the growth of $A$. butzleri, eliminating the need for microaerophilic incubation.

Several factors must be considered when evaluating the survival of bacteria in aquatic environments. Temperature and water source, as shown in this study, can play a significant part in survival, as can organism strain variability. An inverse relationship between water temperature and survival for both E. coli and A. butzleri was observed in four different groundwater sources. Furthermore, A. butzleri survival exceeded that of $E$. coli at all three stress temperatures, suggesting that E. coli may not be an appropriate indicator organism for A. butzleri survival in nutrient-deprived groundwater. Further studies should be done in an attempt to determine what effect strain variability has on survival of $A$. butzleri as compared to E. coli.

Another area of concern is the selectivity of existing isolation media. Countless problems may be encountered when attempting to quantify any species of bacteria from an environment. Existing selective media must be sensitive enough to detect stressed cells while being selective enough to inhibit the growth of indigenous flora. The data 
presented in the current study show that only one of these criteria has been met for the existing recovery media for Arcobacter spp. Microcosm studies demonstrated that while selective media can recover between 70 and 80 percent of stressed cells, indigenous flora were only reduced 10 -fold. Isolation and identification of competing flora may prove to be an important step in modifying and/or creating new selective media. Once identified, the susceptibility to antimicrobials of these organisms can be observed and adjustments to selective media made. Additionally, mixed microcosm studies utilizing some of these identified competitors should be carried out to see what effect, if any, organism interaction has on the survival of $A$. butzleri.

Currently, molecular methods are being utilized to detect the presence of Arcobacter spp. in a variety of environmental samples. The accuracy and speed of operation give distinct advantages to molecular technology. However, some limitations were encountered in this study. Due to the presence of large numbers of indigenous flora, molecular methods failed to detect the presence of A. butzleri in several spiked sewage samples before enrichment. Upon $4 \mathrm{~d}$ selective enrichment, however, the samples did prove positive. Also, molecular methods failed to detect $A$. butzleri from a spiked poultry fecal sample after enrichment probably due to the presence of large amounts of particulate matter in the sample. The addition of a nucleic acid purification step may yield better results. Enrichment of arcobacter-positive samples, however, proved to be a very effective method for molecular detection provided that particulate matter was at a minimum in the sample. Cell levels as low as $10^{1} \mathrm{CFU} / \mathrm{ml}$ of $A$. butzleri were able to be detected from sewage after enrichment, regardless of background flora populations. 


\section{APPENDIX}




\section{Determination of $\boldsymbol{A}$. butzleri optimum growth conditions and growth curve.}

In order to determine the optimal conditions for the growth of $A$. butzleri, several oxygen conditions (i.e. aerobic, microaerophilic, and anaerobic) were examined along with two incubation temperatures. Eight $250-\mathrm{ml}$ flasks with $50 \mathrm{ml}$ nutrient broth (NB) were prepared. Each of the 8 flasks were inoculated with $0.01 \mathrm{ml}$ of a $48-\mathrm{h}$ A. butzleri culture and mixed thoroughly. One flask was also prepared as a sterile control. Flasks were incubated under different sets of incubation conditions: $30^{\circ} \mathrm{C}$ aerobic/static; $30^{\circ} \mathrm{C}$ aerobic/shake at $150 \mathrm{rpm} ; 30^{\circ} \mathrm{C}$ microaerophilic/static; $37^{\circ} \mathrm{C}$ microaerophilic/static; $37^{\circ} \mathrm{C}$ aerobic/static; $37^{\circ} \mathrm{C}$ aerobic/shake; $30^{\circ} \mathrm{C}$ anaerobic/static; and $37^{\circ} \mathrm{C}$ anaerobic/static. Following $48 \mathrm{~h}$ incubation, absorbance was measured at $540 \mathrm{~nm}$ using a Spectronic 20 Genesys (Spectronic instruments, Rochester, NY).

Incubation at $30^{\circ} \mathrm{C}$ for $48 \mathrm{~h}$ under aerobic, static conditions produced maximal biomass (Figure 9). The least favorable conditions for growth occurred under anaerobiosis, regardless of incubation temperature. Although the organism is considered microaerophilic, more biomass was produced under aerobic/static conditions compared to a microaerophilic environment. This may be due to the fact that the test culture had been continually cultured and grown under aerobic conditions. Arcobacters do not grow nearly as well under aerobic conditions upon initial isolation from the environment (7). However, after isolation and subculture, aerobic incubation may prove to be as effective an incubation condition as microaerophilic is known to be.

Next, $50 \mathrm{ml}$ of NB was inoculated with $A$. butzleri and incubated under aerobic, static conditions at $30^{\circ} \mathrm{C}$. Following $48 \mathrm{~h}$ incubation, the organism was subcultured in fresh NB (100 ml) for determination of the growth curve under identical incubation 


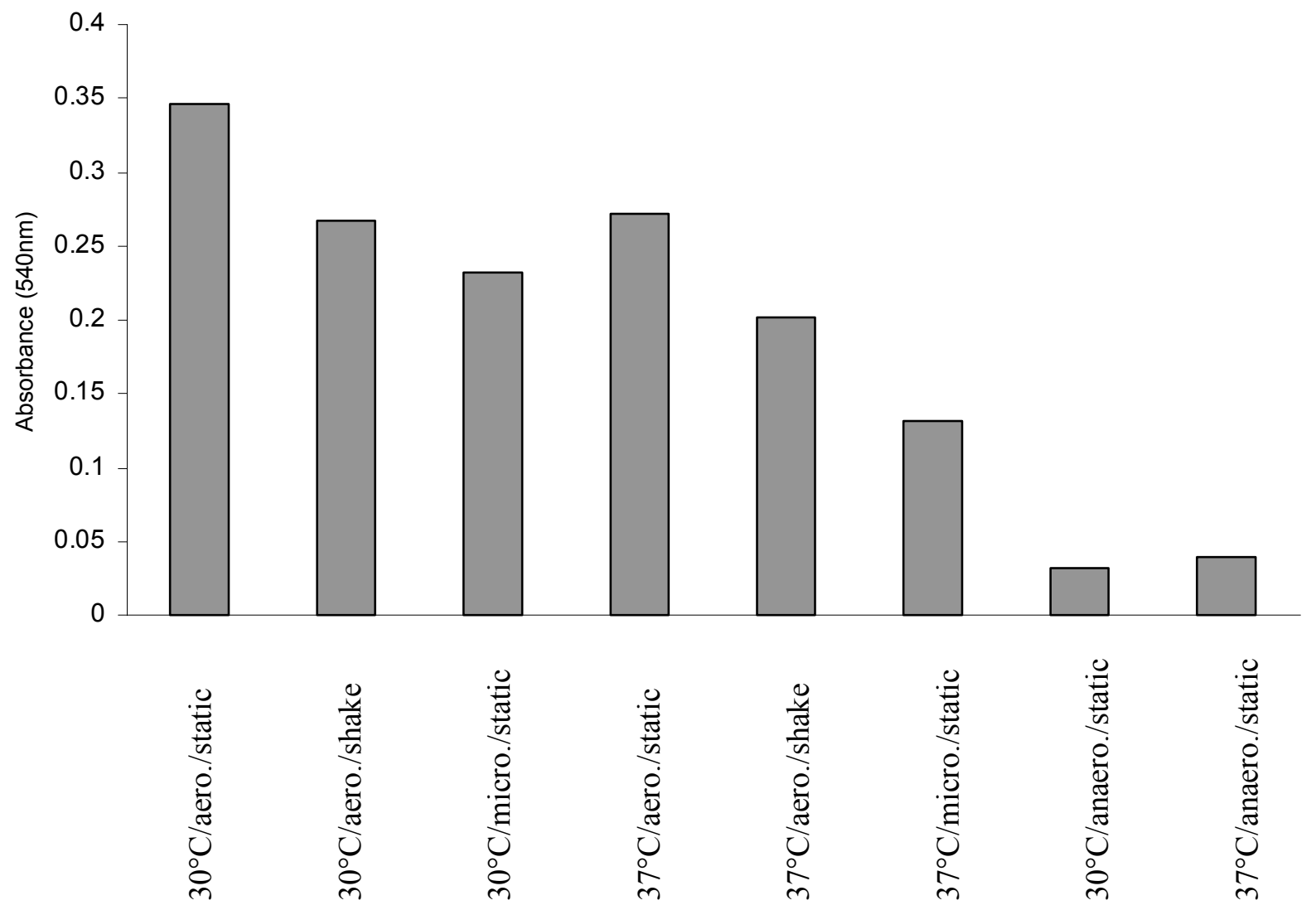

FIG. 9. Absorbance at $540 \mathrm{~nm}$ of $A$. butzleri cultures grown in NB under different incubation conditions. Cultures were incubated for $48 \mathrm{~h}$. 
conditions. Samples were removed periodically over a $53 \mathrm{~h}$ incubation period for spread plate analysis. A culture grown aerobically in $100 \mathrm{ml}$ of nutrient broth under static conditions reached stationary phase after about 18-20 h (Figure 10).

Physical and chemical characterization of groundwater samples. Each of the water samples used throughout the microcosm experiments was analyzed for several chemical/physical characteristics. Raw, autoclaved, and filter-sterilized samples were tested for $\mathrm{Ca}, \mathrm{Mg}, \mathrm{Ba}, \mathrm{Al}, \mathrm{Cu}, \mathrm{Fe}, \mathrm{Mn}$, and $\mathrm{P}$ by Inductively Coupled Plasma (ICP) Spectroscopy on a Perkin-Elmer P-400. Raw, autoclaved and filter-sterilized samples were also tested for $\mathrm{Na}$ and $\mathrm{K}$ using atomic absorption spectroscopy on a Perkin-Elmer AAanalyst. Filter-sterilized samples were analyzed using methods cited in the EPA Water Analysis Manual. pH was analyzed using method 150.1; acidity, 305.1; conductance, 120.1; sulfate 375.4; and chloride using method 325.2. Values for Al, Fe, Mn, $\mathrm{P}$, acidity, and $\mathrm{Cu}$ (except for sample P2) were at or near detection limits and may be unreliable. For each sample, water was collected and stored at $5^{\circ} \mathrm{C}$ until transported to the laboratory. Each sample was analyzed within 24 hours of collection. Results are given in Table 16. 


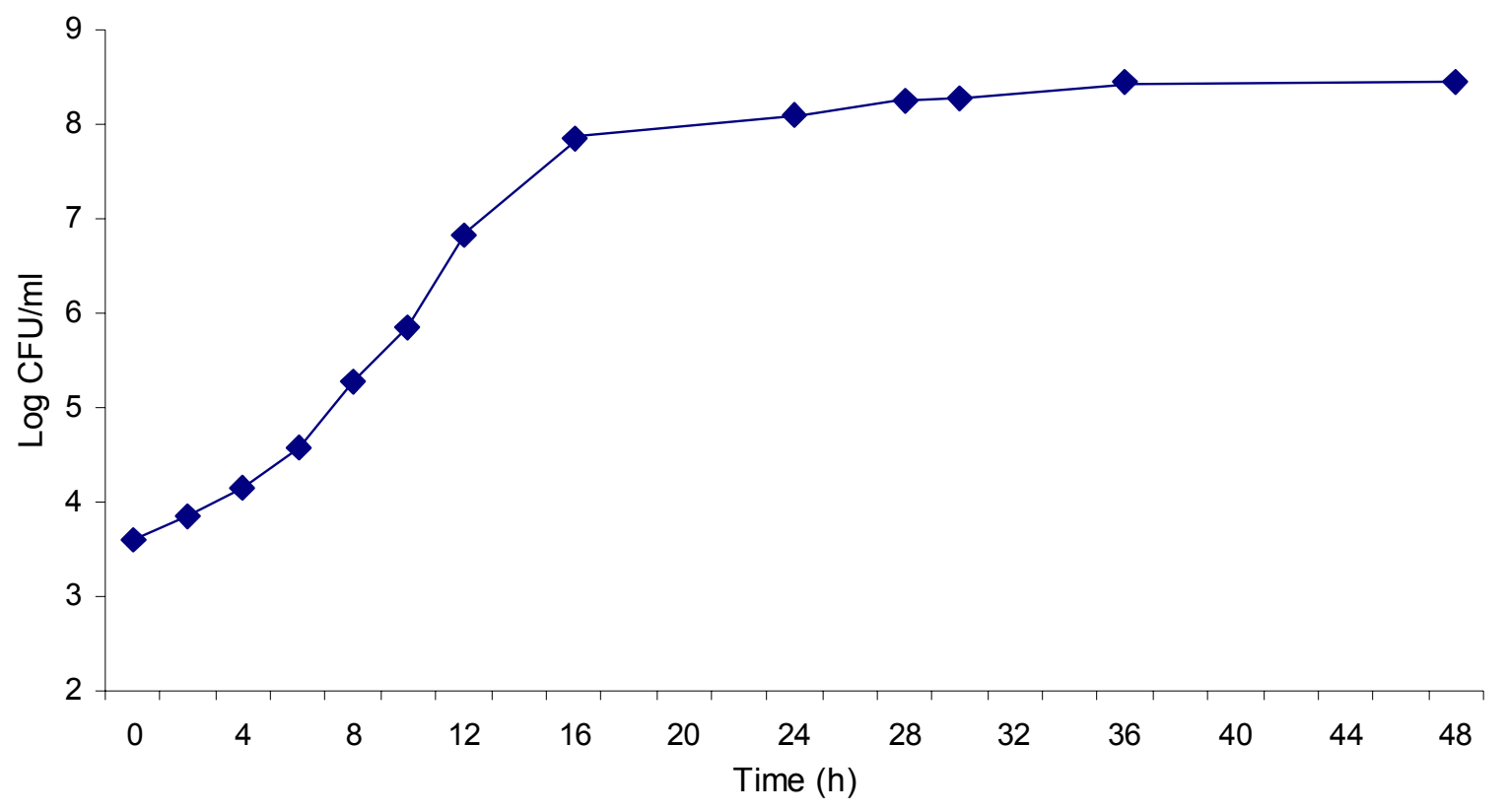

FIG. 10. Arcobacter butzleri growth curve as determined in $\mathrm{NB}$ at $30^{\circ} \mathrm{C}$ during a $2 \mathrm{~d}$ period. Plate counts were preformed on TSABL incubated aerobically at $30^{\circ} \mathrm{C}$ for $48 \mathrm{~h}$. Each point represents the arithmetic mean of duplicate plates. 
TABLE 16. Chemical and physical analyses ( $\mathrm{mg} / \mathrm{l})$ of groundwater used in microcosm studies

\begin{tabular}{|c|c|c|c|c|c|c|c|c|c|c|}
\hline \multirow[b]{2}{*}{ Source } & \multirow[b]{2}{*}{$\mathrm{pH}$} & \multirow[b]{2}{*}{ Conductance } & \multirow[b]{2}{*}{$\mathrm{Na}$} & \multirow[b]{2}{*}{$\mathrm{K}$} & \multicolumn{6}{|c|}{ Measurement ${ }^{\mathrm{a}}$} \\
\hline & & & & & $\mathrm{Ca}$ & $\mathrm{Mg}$ & $\mathrm{Ba}$ & $\mathrm{Cu}$ & $\mathrm{SO}_{4}$ & $\mathrm{Cl}$ \\
\hline S (raw) & $\mathrm{ND}^{\mathrm{b}}$ & ND & 2.26 & 0.75 & 28.37 & 7.71 & 0.12 & 0.01 & ND & $\mathrm{ND}$ \\
\hline $\mathrm{S}$ (filtered) & 7.53 & 177 & 2.31 & 0.75 & 28.92 & 7.31 & 0.11 & 0.01 & $<10$ & $<1$ \\
\hline S (autoclaved) & ND & ND & 2.43 & 0.80 & 29.86 & 8.06 & 0.12 & 0.01 & ND & ND \\
\hline P1 (raw) & ND & ND & 52.84 & 0.97 & 11.21 & 3.69 & 0.07 & 0.03 & ND & ND \\
\hline P1 (filtered) & 7.57 & 289 & 53.05 & 0.98 & 11.09 & 3.92 & 0.08 & 0.03 & 11.3 & 3.96 \\
\hline P1 (autoclaved) & ND & ND & 54.68 & 1.02 & 11.55 & 4.02 & 0.08 & 0.01 & ND & ND \\
\hline P2 (raw) & ND & ND & 1.05 & 0.39 & 11.04 & 2.70 & 0.03 & 0.90 & ND & ND \\
\hline P2 (filtered) & 6.46 & 79 & 1.10 & 0.40 & 11.61 & 2.82 & 0.05 & 0.89 & $<10$ & 1.29 \\
\hline P2 (autoclaved) & ND & ND & 1.58 & 0.42 & 11.69 & 2.91 & 0.03 & 0.85 & ND & ND \\
\hline VP (raw) & ND & ND & 7.41 & 3.03 & 37.50 & 8.57 & 1.16 & ND & ND & ND \\
\hline VP (filtered) & 7.37 & 260 & 7.60 & 3.04 & 38.95 & 8.83 & 1.21 & ND & $<10$ & $<1$ \\
\hline VP (autoclaved) & ND & ND & 7.84 & 3.21 & 40.06 & 9.32 & 1.26 & 0.01 & ND & ND \\
\hline
\end{tabular}

${ }^{\mathrm{a}} \mathrm{All}$ values are $\mathrm{mg} / \mathrm{l}$ except $\mathrm{pH}$ and conductance (umhos/cm).

${ }^{\mathrm{b}}$ Not determined. 


\section{Literature Cited}

1. American Public Health Association. 1998. Standard Methods for the Examination of Water and Wastewater, $20^{\text {th }}$ edn. Washington, DC: American Public Health Association.

2. Atabay, H. I., J. E. L. Corry, and S. L. W. On. 1997. Diversity and prevelance of Arcobacter spp. in broiler chickens. J. Appl. Microbiol. 84:1007-1016.

3. Atabay, H. I., and J. E. L. Corry. 1998. Evaluation of a new Arcobacter enrichment medium and comparison with two media developed for the enrichment of Campylobacter spp. Intl. J. Food Microbiol. 14:53-58.

4. Collins, C. I., I. V. Wesley, and E. A. Murano. 1996. Detection of Arcobacter spp. in ground pork by modified plating methods. J. Food Prot. 59:448-452.

5. Collins, C. I., E. A. Murano, and I. V. Wesley. 1996. Survival of Arcobacter butzleri and Campylobacter jejuni after irradiation treatment in vacuum-packaged ground pork. J. Food Prot. 59:1164-1166.

6. Corry, J. E. L., and H. I. Atabay. 1997. Comparison of the productivity of cefoperazone amphotericin teicoplanin (CAT) agar and modified charcoal cefoperazone deoxycholate (mCCD) agar for various strains of Campylobacter, Arcobacter and Helicobacter pullorum. Intl. J. Food Microbiol. 38:201-209.

7. de Boer, E., J. J. H. C. Tilburg, D. L. Woodward, H. Lior, and W. M. Johnson. 1996. A selective medium for the isolation of Arcobacter from meats. Lett. Appl. Microbiol. 23:64-66.

8. de Oliveira, S. J., A. L. Baetz, I. V. Wealey, and K. M. Harmon. 1997. Classification of Arcobacter species isolated from aborted pig fetuses and sows with reproductive problems in Brazil. Vet. Microbiol. 57:347-354.

9. Ducluzeau, R., S. Hadault, and J. V. Galpin. 1976. Longevity of various bacterial strains of intestinal origin in gas-free mineral water. Euro. J. Appl. Microbiol. 3:227236.

10. Ellis, W. A., S. D. Neill, J. J. O'Brien, H. W. Ferguson, and J. Hanna. 1977. Isolation of Spirillium/Vibrio-like organisms from bovine fetuses. Vet. Rec. 100:451-452. 
11. Enberg, J., S. L. W. On, C. S. Harrington, and P. Gerner-Smidt. 2000. Prevalence of Campylobacter, Arcobacter, Helicobacter, and Sutterella spp. in human fecal samples as estimated by a reevaluation of isolation methods for Campylobacters. J. Clin. Microbiol. 38:286-291.

12. Fish, J. T., and G. W. Pettibone. 1995. Influence of freshwater sediment on the survival of Escherichia coli and Salmonella spp. as measured by three methods of enumeration. Lett. Appl. Microbiol. 20:277-281.

13. Gevertz, D., A. J. Telang, G. Voordouw, and G. E. Jenneman. 2000. Isolation and characterization of strains CVO and FWKO B, two novel nitrate-reducing, sulfide oxidizing bacteria isolated from oil field brine. Appl. Environ. Microbiol. 66:2491-2501.

14. Harmon, K. M., and I. V. Wesley. 1997. Multiplex PCR for the identification of Arcobacter and differentiation of Arcobacter butzleri from other arcobacters. Vet. Microbiol. 58:215-227.

15. Harmon, K. M., and I. V. Wesley. 1996. Identification of Arcobacter isolates by PCR. Lett. Appl. Microbiol. 23:241-244.

16. Harrab, B, S. Schwarz, and S. Wenzel. 1998. Identification of Arcobacter isolates from broilers by biochemical tests, antimicrobial resistance patterns and plasmid analysis. J. Vet. Med. 45:87-94.

17. Higgins, R., S. Messier, D. Daignault, and M. Lorange. 1998. Arcobacter butzleri isolated from a diarrhoeic non-human primate. Laboratory Amimals. 33:87-90.

18. Houf, K., L. A. Devriese, L. D. Zutter, J. V. Hoof, and P. Vandamme. 2001. Susceptibility of Arcobacter butzleri, Arcobacter cryaerophilus, and Arcobacter skirrowii to antimicrobial agents used in selective media. J. Clin. Microbiol. 39:1654-1656.

19. Houf, K., A. Tutenel, L. D. Zutter, J. V. Hoof, and P. Vandamme. 2000. Development of a multiplex PCR assay for the simultaneous detection and identification of Arcobacter butzleri, Arcobacter cryaerophilus and Arcobacter skirrowii. FEMS Microbiol Lett. 193:89-94.

20. Hsueh, P. R., L. J. Teng, P. C. Yang, S. K. Wang, S. C. Chang, S. W. Ho, W. C. Hsieh, and K. T. Luh. 1997. Bacteremia caused by Arcobacter cryaerophilis 1B. J Clin. Microbiol. 35:489-491.

21. Jacob, J., D. Woodward, I. Feuerpfeli, and W. M. Johnson. 1998. Isolation of Arcobacter butzleri in raw water and drinking water treatment plants in Germany. Zent.bl. Hyg. Umweltmed. 201:189-198. 
22. Johnson, L. G., and E. A. Murano. 1999. Comparison of three protocols for the isolation of Arcobacter from poultry. J. Food. Prot. 62:610-614.

23. Johnson, L. G., and E. A. Murano. 1999. Development of a new medium for the isolation of Arcobacter spp. J. Food Prot. 62:456-462.

24. Kerr, M., M. Fitzgerald, J. J. Sheridan, D. A. McDowell, and I. S. Blair. 1999. Survival of Escherichia coli O157:H7 in bottled natural mineral water. J. Appl. Microbiol. 87:833-841.

25. Korhonen, L. K., and P. J. Martikainen. 1991. Comparison of the survival of Campylobacter jejuni and Campylobacter coli in culturable form in surface water. Can. J. Microbiol. 37:530-533.

26. Korhonen, L.K., and P. J. Martikainen. 1991. Survival of Escherichia coli and Campylobacter jejuni in untreated and filtered lake water. J. Appl.Bacteriol. 71:379382.

27. LeChevallier, M. W., M. Abbaszadegan, A. K. Camper, C. J. Hurst, G. Izaguirre, M. M. Marshall, D. Naumovitz, P. Payment, E. W. Rice, J. Rose, S. Schaub, T. R. Slifko, D. B. Smith, H. V. Smith, C. R. Sterling, and M. Stewart 1999. Committee report: emerging pathogens-bacteria. J. Amer. Watt. Works Assoc. 91:101-109

28. Manke, T. R., I. V. Wesley, J. S. Dickson, and K. M. Harmon. 1998. Prevalence and genetic variability of Arcobacter species in mechanically separated turkey. J. Food Prot. 61:1623-1628.

29. Mansfield, L. P., and S. J. Forsythe. 2000. Arcobacter butzleri, A. skirrowii and A. cryaerophilus - potential emerging human pathogens. Rev. Med. Microbiol. 11:161170.

30. Marshall, S. M., P. L. Melito, D. L. Woodward, W. M. Johnson, F. G. Rodgers, and M.R. Mulvey. 1999. Rapid identification of Campylobacter, Arcobacter, and Helicobacter isolates by PCR-restriction length fragment polymorphism analysis of the 16s rRNA gene. J. Clin. Microbiol. 37:4158-4160.

31. Maugeri, T. L., C. Gugliandolo, M. Carbone, D. Caccamo, and M. T. Fera. 2000. Isolation of Arcobacter spp. from a brackish environment. Microbiologica. 23:143-149.

32. McClung, C. R., D. G. Patriquin, and R. E. Davis. 1983. Campylobacter nitrofigilis sp. nov., a nitrogen-fixing bacterium associated with the roots of Spartina alterniflora Loisel. Int. J. Syst. Bacteriol. 33:605-612. 
33. Meng, J., and M. P. Doyle. 1998. Emerging and evolving microbial foodborne pathogens. Bull. Inst. Pasteur. 96:151-164.

34. Miller, A. J., J. L. Smith, and R. L. Buchanan. 1998. Factors affecting the emergence of new pathogens and research strategies leading to their control. J. Food Safety. 18:243-263.

35. Musmanno, R. A., M. Russi, H. Lior, and N. Figura. 1997. In vitro virulence factors of Arcobacter butzleri strains isolated from superficial water samples. Microbiologica 20:63-68.

36. Nachamkin, I. 1997. Campylobacter and Arcobacter, p. 483-491. In P.R. Murray, E.J. Baron, M.A. Pfaller, F.C. Tenover, and R.H. Yolken (ed.), Manual of clinical microbiology, $6^{\text {th }}$ ed. American Society for Microbiology, Washington, D.C.

37. Neill, S. D., J. N. Campbell, J. J. O'Brien, S. T. C. Weatherup, and W. A. Ellis. 1985. Taxonomic position of Campylobacter cryaerophila sp. nov. Int. J. Syst. Bacteriol. 35:342-356.

38. On, S. L. W. 2001. Taxonomy of Campylobacter, Arcobacter, Helicobacter and related bacteria: current status, future prospects and immediate concerns. J. Appl. Microbiol. 90:1S-15S.

39. Phillips, C. A. 1999. The effect of citric acid, lactic acid, sodium citrate and sodium lactate, alone and in combination with nisin, on the growth of Arcobacter butzleri. Lett. Appl. Microbiol. 29:424-428.

40. Phillips, C. A. 2001. Arcobacters as emerging human foodborne pathogens. Food Control. 12:1-6.

41. Rice, E. W., C. H. Johnson, D. K. Wild, and D. J. Reasoner. 1992. Survival of Escherichia coli $\mathrm{O} 157: \mathrm{H7}$ in drinking water associated with a waterborne disease outbreak of hemorrhagic colitis. Lett. Appl. Microbiol. 15:38-40.

42. Rice, E. W., M. R. Rodgers, I. V. Wesley, C. H. Johnson, and S. A. Tanner. 1999. Isolation of Arcobacter butzleri from ground water. Lett. Appl. Microbiol. 28:31-35.

43. Ridsdale, J. A., H. I. Atabay, and J. E. L. Corry. 1999. Campylobacter and Arcobacter spp. isolated from the carcasses and caeca of commercially reared ducks. Anaerobe. 5:317-320.

44. Ridsdale, J. A., H. I. Atabay, and J. E. L. Corry. 1998. Prevelance of campylobacters and arcobacters in ducks at the abattoir. J. Appl. Microbiol. 85:567573. 
45. Rollins, D. M., and R. R. Colwell. 1986. Viable but nonculturable stage of Campylobacter jejuni and its role in survival in the natural aquatic environment. Appl. Environ. Microbiol. 52:531-538.

46. Skirrow, M. B. 1994. Diseases due to Campylobacter, Helicobacter, and related bacteria. J. Comp. Path. 111:113-149.

47. Snaidr, J., R. Amann, I. Huber, W. Ludwig, and K. H. Schleifer. 1997. Phylogenetic analysis and in situ identification of bacteria in activated sludge. Appl. Environ. Microbiol. 63:2884-2896.

48. Stampi, S., G. DeLuca, O. Varoli, and F. Zanetti. 1999. Occurrence, removal and seasonal variation of thermophilic Campylobacters and Arcobacter in sewage sludge. Zbl. Hyg. Umweltmed. 202:19-27

49. Suarez, D. L., I. V. Wesley, and D. J. Larson. Detection of Arcobacter species in gastric samples from swine. Vet. Microbiol. 57:325-336.

50. Telang, A. J., G. E. Jenneman, and G. Voordouw. 1999. Sulfur cycling in mixed cultures of sulfide-oxidizing and sulfate- or sulfur-reducing oil field bacteria. Can. J. Microbiol. 45:905-913.

51. Terzieva, S. I., and G. A. McFeters. 1991. Survival and injury of Escherichia coli, Campylobacter jejuni, and Yersinia enterocolitica in stream water. Can. J. Microbiol. 37:785-790.

52. Thamdrup, B., R. Rossello-Mora, and R. Amann. 2000. Microbial manganese and sulfate reduction in Black Sea shelf sediments. Appl. Environ. Microbiol. 66:2888-2897.

53. Thomas, C., D. J. Hill, and M. Mabey. 1999. Evaluation of the effect of temperature and nutrients on the survival of Campylobacter spp. in water microcosms. J. Appl. Microbiol. 86:1024-1032.

54. Thompson, L. M. III, R. M. Smibert, J. L. Johnson, and N. R. Krieg. 1988. Phylogenetic study of the genus Campylobacter. Int. J. Syst. Bacteriol. 41:451-455.

55. Vandamme, P., E. Falsen, R. Rossau, B. Hoste, P. Segers, R. Tytgat, and J. De Ley. 1991. Revision of Campylobacter, Helicobacter, and Wolinella taxonomy: emendation of generic descriptions and proposal of Arcobacter gen. nov. Int. J. Syst. Bacteriol. 41:88-103. 
56. Vandamme, P., M. M. Vancanneyt, B. Pot, L. Mels, B. Hoste, D. Dewettinck, L. Vlaes, C. Van Den Burre, R. Higgens, J. Hommez, K. Kersters, J.-P. Butzler, and H. Goossens. 1992. Polyphasic taxonomic study of the emended genus Arcobacter with Arcobacter butzleri comb. nov. \& Arcobacter skirrowii sp. nov., an aerotolerant bacterium isolated from veterinary specimens. Int. J. Syst. Bacteriol. 42:344-356.

57. Wantanabe, K., K. Wantanabe, Y. Kodama, K. Syutsubo, and S. Harayama. 2000. Molecular characterization of bacterial populations in petroleum-contaminated groundwater discharged from underground crude oil storage cavities. Appl. Environ. Micro. 66:4803-4809.

58. Wesley, I. V. 1994. Arcobacter infections. p.181-190 In G.W. Beran, J.H. Steele (ed.) Handbook of Zoonoses $2^{\text {nd }}$ ed. sec. A: Bacterial, Rickettsial, Chlamydial, and Mycotic. $2^{\text {nd }}$ ed. CRC Press, Salem, MA.

59. Wesley, I. V. 1996. Helicobacter and Arcobacter species: Risks for foods and beverages. J. Food Prot. 59:1127-1132.

60. Wesley, I. V. 1997. Helicobacter and Arcobacter: Potential human foodborne pathogens? Trends in Food Sci. Tech. 8:293-299.

61. Wesley, I. V., and A. L. Baetz. 1999. Natural and experimental infections of Arcobacter in poultry. Poul. Sci. 78:536-545.

62. Wesley, I. V., A. L. Baetz, and D. J. Larson. 1996. Infection of cesarean-derived colostrum-deprived 1-day-old piglets with Arcobacter butzleri, Arcobacter cryaerophilus, and Arcobacter skirrowii. Infect. Immun. 64:2295-2299.

63. Wesley, I. V., S. J. Wells, K. M. Harmon, A. Green, L. Schroeder-Tucker, M. Glover, and I. Siddique. 2000. Fecal shedding of Campylobacter and Arcobacter spp. in dairy cattle. Appl. Environ. Microbiol. 66:1994-2000.

64. Yan, J. J., W. C. Ko, A. H. Huang, H. M. Chen, Y. T. Jin, and J. J. Wu. 2000. Arcobacter butzleri bacteremia in a patient with liver cirrhosis. J. Formos Med. Assoc. 99:166-169.

65. Zanetti, F., O. Varoli, S. Stampi, and G. DeLuca. 1996. Prevalence of thermophilic Campylobacter and Arcobacter butzleri in food of animal origin. Internat. J. Food Microbiol. 33:315-321. 


\section{VITAE}

Robert Darrell McElwain was born on July 16, 1976 in Erie, Pennsylvania. He was raised in Hamburg, NY and graduated from Hamburg High School in 1994. He received his BS in biology from Gannon University in Erie, Pennsylvania in 1998. While at Gannon University he played 4 years of varsity golf and was an active member of the Pi Kappa Alpha Fraternity. He joined the graduate program in Environmental Microbiology at West Virginia University in August of 1999 and will complete his degree requirements in 2002. He is currently working as a microbiologist with the United States Food and Drug Administration in Atlanta, Georgia’s Southeast Regional Laboratory. 